Relational Contracts, the Cost of Enforcing Formal Contracts, and Capital Structure Choice

Theory and Evidence

\author{
by \\ Matthias FAHN \\ Valeria MERLO \\ Georg WAMSER \\ Working Paper No. 1711 \\ July 2017
}

Johannes Kepler University of Linz Department of Economics Altenberger Strasse 69 A-4040 Linz - Auhof, Austria www.econ.jku.at 


\title{
Relational Contracts, the Cost of Enforcing Formal Contracts, and Capital Structure Choice* Theory and Evidence
}

\author{
Matthias Fahn† Valeria Merloł Georg Wamser ${ }^{\ddagger}$
}

June 22, 2017

\begin{abstract}
This paper shows that the cost of enforcing contracts governing non-financial relationships between firms affects a firm's financing structure. We analyze the interaction between a firm's capital structure and the type of contracts it uses to deal with its suppliers. We first develop a theoretical model where a downstream party needs an intermediate good from an upstream party, and this intermediate good can be of high or low quality. Court-enforceable contracts can be used to enforce high quality, but their use is costly. If these costs are too high, relational contracts - self-enforcing informal arrangements that can be sustained in long-term relationships - are needed. Relational contracts, though, can only be sustained if debt is not too high. The reason is that a firm's commitment in relational contracts is determined by its future profits in the cooperative relationship, and the need to repay debt reduces future profits. We therefore derive the prediction that, on average, higher costs of enforcing formal contracts should be associated with firms having less leverage. We test this prediction with the help of two datasets. First, the Microdatabase Directinvestment (MIDI) provided by Deutsche Bundesbank, which records balance-sheet information on the universe of German investments abroad, including detailed information on external debt and equity capital. Second, the World Bank's Doing Business Database, which provides information on the average cost of enforcing (formal) contracts between a firm and a supplier of an intermediate good. Using a panel data model for fractional response variables, we can show that an increase in the cost of enforcing contracts in a country makes firms use substantially more equity financing.
\end{abstract}

${ }^{*}$ We thank Daniel Barron, Sylvain Chassang, Thomas Fackler, Bob Gibbons, Luigi Guiso, Hendrik Hakenes, Martin Kanz, Mike Powell, Antoinette Schoar, Kathryn Spier, and seminar participants in Bonn, Hohenheim, Munich, Tübingen, WHU Koblenz, the 1st Lecture on the Economics of Organizations and Human Resources (Frankfurt), and the 2017 annual meeting of the Royal Economic Society (Bristol), for helpful comments. We are grateful to Deutsche Bundesbank for granting access to MiDI.

${ }^{\dagger}$ Affiliation: University of Munich and CESifo. LMU Munich, Chair of Organizational Economics, Kaulbachstraße 45, 80539 München, Germany. E-mail: matthias.fahn@econ.lmu.de

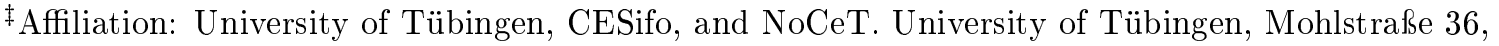
72074 Tübingen, Germany. E-mail: E-mail: valeria.merlo@uni-tuebingen.de.

$\S$ Affiliation: University of Tübingen, CESifo, and NoCeT. University of Tübingen, Mohlstraße 36, 72074 Tübingen, Germany. E-mail: georg.wamser@uni-tuebingen.de. 


\section{Introduction}

It is generally recognized that legal institutions affect economic outcomes. But very little is actually known about the channels through which legal institutions affect firms' organizational structures. This paper explores how the quality of one particular legal institution - the enforceability of legal contracts - affects a particular choice made by the firm, namely its financing decision. We make the empirical observation that higher costs of enforcing formal contracts - which govern non-financial relationships between firms are negatively related to firms' leverage. We theoretically derive a mechanism that can explain this outcome. This mechanism has two main components: First, higher costs of enforcing formal contracts make firms rely more on informal arrangements ("relational contracts") in order to govern their relationships. Second, informal arrangements work better if firms use less leverage. This is because a firm's commitment in relational contracts is determined by its future rents from the cooperative relationship, and the need to repay debt reduces those future rents.

We show that the quality of institutions can have an indirect effect on a firm's organizational structure, because both aspects influence a firm's relationships with its stakeholders. In particular, we consider an ongoing supply relationship involving an upstream party (supplier), a downstream party (buyer), and the delivery of a customized intermediate good. Our setting entails a classic hold-up problem: given the inability to recover sunk costs, the upstream party is vulnerable to the downstream party refusing to pay for the delivery of high quality. Hence, ensuring high quality requires an enforceable arrangement between the parties. While court-enforceable contracts can be written, their use is costly. If those enforcement costs are too high because institutions are bad, both parties have to rely on other means to ensure high quality, like informal self-enforcing arrangements. The optimal arrangement is not only affected by the cost of enforcing formal contracts (that is, the institutional environment), though, but also by how the downstream party finances its operations (that is, its financing structure). Debt financing restricts the set of feasible arrangements to enforce high quality, because it reduces what is at stake for the downstream party.

Our theoretical findings are consistent with the negative correlation between the cost of contract enforcement and average firm leverage, which we observe in different datasets. We base our analysis on a measure of contract enforcement costs across countries provided by the World Bank through its Doing Business database. The variable Cost to enforce a contract (in \% of claim) measures court costs, enforcement costs 
and average attorney fees associated with the resolution of a hypothetical commercial dispute between a seller and a buyer through a local court.

Figure 1 plots average debt ratios across countries against the cost of enforcing a contract for two samples. Panel (a) is based on data from the Orbis database, where we measure the long-term-debt-to-capital ratio on the vertical axis. Panel (b) is based on data from the MiDi database, where we measure the external-debt-to-capital ratio on the vertical axis. ${ }^{1}$ There is a clear negative correlation between average leverage (measured as the mean debt ratio across all observations in a given country) and contract enforcement costs. This unconditional negative relationship between debt-to-asset ratios and contract enforcement costs holds in regression analyses below, where all relevant determinants of leverage are controlled for.

Figure 1: Correlation between debt and the cost to enforce a contract

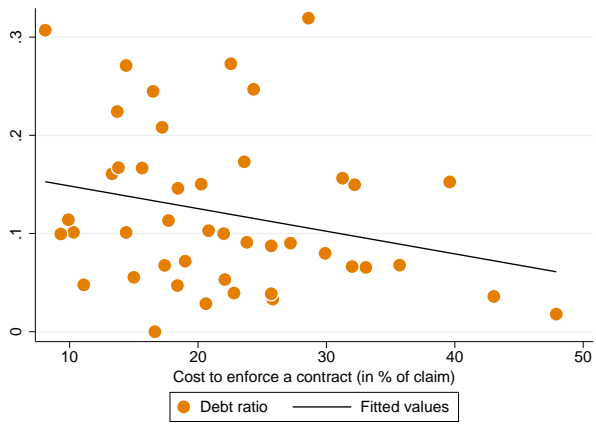

(a) Mean debt ratio (source: Orbis)

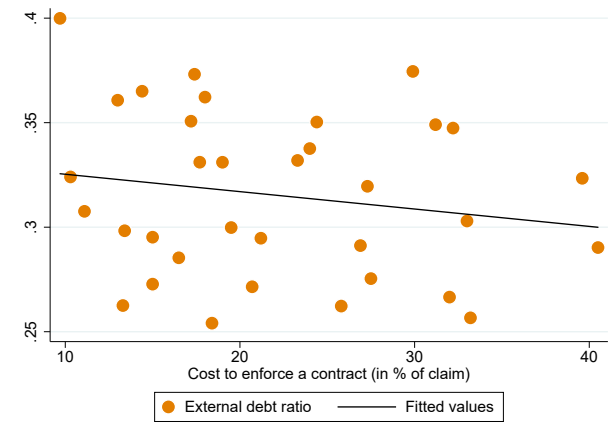

(b) Mean external debt ratio (source: MiDI)

To explain the link between contract enforcement costs and financing decisions, we develop a theoretical model that picks up the main features of the hypothetical case behind the World Bank's Doing Business cost to enforce a contract measure. The latter assumes a dispute arising from the delivery of custom-made goods by the seller, for which the buyer refuses to pay, alleging inadequate quality. Subsequently, the seller sues the buyer referring to their sales agreement. An expert opinion is given and the

\footnotetext{
${ }^{1}$ Note that the latter dataset is used for most of our empirical analysis below since MiDi is censustype data and reports external debt, which is our preferred measure of debt financing for the purpose of our paper. Both graphs only report average values of debt ratios per country if the mean is based on at least 100 observations. This excludes some countries with very high values in the variable cost to enforce a contract.
} 
judge decides that the quality of the good delivered is adequate and that the buyer must pay the contracted price. The total cost related to such a case include all costs advanced by the seller to the court, to enforce the judgment, and to a local attorney regardless of final reimbursement. ${ }^{2}$

Accordingly, our model involves two firms, an upstream and a downstream party. The downstream party needs a physical investment good and an intermediate good in order to operate. The investment good is acquired once, and can be financed by debt or equity. An intermediate good is needed in every period of the infinite-horizon game. The intermediate good can only be produced by the upstream party, and is of value to the downstream party only if the upstream party provides high quality. But providing high quality is costly for the upstream party, who needs to be reimbursed accordingly. The arrangement between upstream and downstream party can either take the form of a formal spot contract or a long-term arrangement. If a formal spot contract is used, and the downstream party refuses to pay the determined price - claiming that quality is low - the upstream party can sue the downstream party. If quality has been high, the upstream party wins the trial, but has to bear costs of contract enforcement. If those costs are too high, the upstream party has no incentives to sue the buyer and the hold-up problem prevails. Anticipating the downstream party's possible refusal to pay, the upstream party has no incentive to provide high quality in the first place. Hence, formal spot contracts have no bite if costs of contract enforcement are too high. To enforce high quality, players must rely on other means, namely long-term arrangements. Those either are purely informal or a combination of formal and informal elements. A purely informal arrangement, a so-called relational contract, is optimal for rather high costs of enforcing formal contracts. There, the downstream party promises to reward the upstream party for the delivery of a high-quality intermediate good. This promise is credible if the downstream party's future profits are sufficiently high, compared to the profits after reneging on this promise.

For intermediate costs of enforcing formal contracts, a long-term arrangement that contains a combination of formal and informal components is optimal. With this arrangement, the upstream party also sues the downstream party in case the latter refuses to pay. Since the enforcement costs are relatively high, continuation play off the equilibrium path must involve a sufficiently high rent for the upstream party.

All these arrangements are affected by how the downstream party finances the physi-

\footnotetext{
${ }^{2}$ See http://www.doingbusiness.org/methodology/enforcing-contracts, for more details on how this case is constructed.
} 
cal investment. The downstream party can either use equity or debt, where in the latter case there is access to a competitive credit market. If using debt, the downstream party must have an incentive to meet all repayment obligations. We assume that after a default, the downstream party is liquidated and loses access to future rents generated by its assets. Therefore, the downstream party's repayment obligations must not exceed its (discounted) future profits. This determines a maximum-debt threshold.

While this maximum-debt threshold is sufficient in case formal spot contracts are used, long-term arrangements involve additional conditions that further restrict the downstream party's maximum amount of debt. With formal enforcement in long-term arrangements, the upstream party must receive a sufficiently high rent off the equilibrium path, where this rent increases in the cost of contract enforcement. But this reduces the downstream party's off-path profits and therefore its off-path incentives to repay debt, hence the downstream party's maximum feasible debt is further restricted. Relational contracts require the downstream party's payment obligations to the supplier to not exceed her future rents net of debt repayments. Therefore, more debt and consequently higher repayment obligations - also increases the downstream party's reneging temptation in the relational contract. This negative effect of leverage on the enforceability of relational contracts further reduces the maximum debt threshold if relational contracts are used. Thus, a downstream party's debt should generally be lower if long-term arrangements are employed, and within long-term arrangements, it should be lower under relational contracts than with formal enforcement.

This relationship gives an explanation for the aforementioned empirical observation that higher costs of enforcing formal contracts are associated with lower average debt levels of firms. If those costs are low, firms use formal spot contracts and have the least restrictions regarding their use of debt. For intermediate cost levels, firms use formal enforcement in long-term arrangements. Then, their use of debt is more restricted than with formal spot contracts. For rather high costs of enforcing contracts, firms use relational contracts, which impose the tightest restriction on possible debt levels.

Using firm-level panel data, we test our prediction that in the presence of high costs of enforcing a contract, firms should have lower leverage levels. In particular, we examine how the share of debt provided by external creditors in total capital is determined by the cost of enforcing a contract and other variables determining debt financing, using a fractional response estimation approach. The latter nonlinear model recognizes the bounded nature of the dependent variable, i.e., the debt share, and allows us to control for observed and unobserved country-, sector-, and firm-heterogeneity. Consistent with 
our theory, our empirical results suggest that higher costs to enforce a contract are associated with a lower external-debt-to-capital ratio. Increasing the cost of contract enforcement from the mean by one standard deviation leads to a 1.27 percentage point lower debt-to-capital ratio. The empirical results are robust to numerous additional tests, including tests on specific features and predictions produced by our theoretical model.

We finally compare average firms facing different costs of enforcing contracts. The aim of the latter exercise is to learn how much of the difference in debt-to-capital ratios can be explained through the institutional environment under which firms operate. In 2012, for example, the cost of enforcing contracts amounted to $18.4 \%$ and $22.3 \%$ of the claim in the U.S. and Canada, respectively. Our estimations imply that, under the higher Canadian contract enforcement cost, the average U.S. firm would have a 0.9 percentage points lower external-debt-to-capital ratio.

\section{Related Literature}

This paper relates to the corporate finance literature. Existing theories of a firm's optimal capital structure seem to do an insufficient job in explaining why many healthy and profitable firms rely heavily on equity financing, even though benefits associated with debt (like tax shields) appear to be high and the bankruptcy risk low (Graham, 2000; Strebulaev and Yang, 2013). Most approaches focus on how different modes of financing affect the owners of a firm, its managers, and (potential) providers of external capital. More recently, there has been a growing awareness that a firm's optimal capital structure is also affected by its relationships with non-financial stakeholders - such as employees or suppliers. In a survey article, Graham and Leary (2011) call for new approaches to explain a firm's optimal capital structure considering interactions with non-financial stakeholders. Early approaches in this direction include Titman (1984), Maksimovic and Titman (1991), or Berk, Stanton, and Zechner (2010). More recently, a number of papers have established that a firm's capital structure might interact with informal components of a firm's incentive system. Fahn et al. (2017), or Barron and Li (2016) show theoretically that relational contracts work less smoothly if a firm uses more debt financing. ${ }^{3}$ This is because the performance of relational contracts is determined by

\footnotetext{
${ }^{3}$ See Malcomson (2013) for a great overview on relational contracts, and Gibbons and Henderson (2013) for a thorough reasoning for why the appropriate handling of relational contracts is crucial for a firm's success.
} 
the size of future quasi-rents stemming from the respective relationship. Debt reduces those quasi-rents because of the associated payments to creditors. While plenty of anecdotal evidence exists for the negative effect of debt financing on the performance of relational contracts, we are, to our knowledge, the first to provide systematic empirical evidence.

Our paper is also related to the literature on contract enforceability. In contract theory, the issue of the enforceability of contracts has largely been ignored. The literature has mostly focused on the two extreme cases that either external enforcement is automatically carried out free of cost, or that external enforcement is not feasible. Exeptions are Martimort et al. (2016) who assume that external enforcement exists, but that breaching a formal contract is feasible at some cost. Battigalli and Maggi (2008) assume that writing a formal contract is costly. In a multitasking setting where formal contracts can be written on any sub-task, they show that formal and implicit contracts are generally used together. To the contrary, in our model we assume that costs only accrue if a contract has to be enforced by a court.

A few papers have also incorporated the assumption that enforcing formal contracts is not for free. These papers analyze the relationship between firms and its final customers, where costly litigation can be used as an incentive device for firms to provide high-quality products, but where firms also have the possibility to build up a reputation. Bakos and Dellarocas (2011) show that if quality can be low even if high effort has been provided, a reputation mechanism is generally inferior to a litigation mechanism - unless the latter is rather costly or adverse selection is a severe problem. Ganuza et al. (2016) suggest that a better-functioning litigation mechanism generally also improves the reputation mechanism, and Baker and Choi (2016) show that the interaction between formal contracts and reputation can also be driven by information from past litigation cases.

In a different vein, a number of important contributions (cf. Baker et al., 1994) have analyzed different degrees of verifiability of performance measures. If some performance measures are verifiable whereas others are not, formal and informal arrangements (i.e., relational contracts) can be substitutes if the former serve as outside options for a relational contract. We do not consider different degrees of verifiability, but rather assume that external enforcement of a contract is feasible but costly. If those costs are sufficiently low, only formal enforcement is used. Otherwise, other contractual means are required to sustain high quality.

Finally, our paper relates to the growing literature on the role of institutions for 
economic outcomes. Institutions are recognized to be a key determinant of long-term growth (Acemoglu et al., 2005), financial development (La Porta et al., 2008), and international trade (Nunn and Trefler, 2014). We contribute to this literature by adding to the understanding of the precise channels through which legal institutions affect market outcomes, in our case the financing decision of the firm. Most papers linking legal institutions to capital structure focus on the effect of investor protection and creditor rights. Shleifer and Wolfenzon (2002) summarize empirical evidence and show that it is consistent with an agency model of corporate finance where external financing is determined by the quality of investor protection. Contract enforcement efficiency has been analyzed in the context of debt enforcement, and has been found to be correlated to debt market development (Djankov et al., 2006). Nunn (2007) finds that the quality of contract enforcement determines a country's trade patterns: countries with good contract enforcement specialize in industries for which relationship-specific investments are most important. Boehm (2013) finds that in countries with high enforcement costs, the sectoral use of inputs relying heavily on contract enforcement is lower. All these studies rely on cross-sectional variation across countries or countries and industries to identify the link between legal institutions and economic outcomes. We are, to the best of our knowledge, the first to explore the link between the cost of enforcing contracts governing non-financial relationships between firms, incentives and the capital structure of the firm. To identify the effect empirically, we exploit a census-type paneldata of multinational firms. This allows us to identify a causal effect of changes in contract enforcement costs in a country on changes in the average debt-to-asset ratio of firms in that country, while controlling for observed and unobserved firm and country characteristics.

\section{Theoretical Analysis}

In this section, we provide a theoretical mechanism that can rationalize the observation that higher costs of enforcing non-financial contracts are associated with firms generally using less debt. 


\subsection{Model}

\subsubsection{Technology}

There are two firms, a downstream party and an upstream party, the time horizon is infinite, time is discrete and players share a common discount factor $\delta<1$. In order to operate, the downstream party needs two inputs - a physical investment good and an intermediate good that can only be produced by the upstream party.

The downstream party requires one unit of the intermediate good in every period $t=1,2, \ldots$. The quality of this good can either be high or low, $q_{t} \in\{0,1\}$, and the upstream party has production $\operatorname{costs} q_{t} c$, with $c>0$. For the downstream party, the intermediate good has a value $q_{t} \theta$, with $\theta>0$. Thus, only a high-quality intermediate good is of value to the downstream party and costly to produce for the upstream party. Upon receiving the intermediate good, the downstream party can generate the value $q_{t} \theta$ at zero marginal cost.

The physical investment good is purchased at the beginning of the game, in period $t=0$. More precisely, the downstream party has to invest an exogenously given amount $I>0$ to get her business running. ${ }^{4}$ To finance $I$, it can either use equity or short-term debt. We assume that the downstream party is not liquidity constrained and has sufficient internal funds to finance $I$ with equity. ${ }^{5}$

The investment good as well as the intermediate good have no outside value. Furthermore, there is no alternative supplier that can produce the specific intermediate good and no alternative intermediate good with positive value for the downstream party. These assumptions have no qualitative impacts on our results, as long as the relationship between upstream party and downstream party has a larger value than alternative opportunities.

Finally, we assume that $\frac{\delta}{1-\delta}(\theta-c)-I>0$. This implies not only that producing high quality is efficient, but also that starting the downstream party's firm is efficient, as well as continuing it in every period.

\footnotetext{
${ }^{4}$ We assume the that upstream party does not need to make such an investment and abstract from the upstream party's financing decision. In Appendix II, in Section 6, we also let the upstream party make an up-front investment.

${ }^{5}$ In Fahn et al. (2017), we analyze a setting where internal funds are not sufficient to finance $I$, and debt as well as external equity is available. Here, we aim at deriving (indirect) costs of debt financing in a setup that is as simple as possible.
} 


\subsubsection{Credit Market}

If the downstream party intends to use debt in order to (partially) finance the investment $I$, it can enter a perfectly competitive credit market at the end of every period $t=0,1,2, \ldots$, where all potential creditors are risk neutral and have a discount factor $\delta$. The amount of debt borrowed in period $t-1$ and used in period $t$ is denoted by $D_{t}(\leq I)$, so that equity amounts to $I-D_{t}$. Interest is denoted by $r_{t}$ and paid at the end of period $t$. Hence, the downstream party repays $\left(1+r_{t}\right) D_{t}$ before it can enter the credit market in period $t+1$ to borrow $D_{t+1}$.

We assume that given high quality has been produced, the downstream party always has sufficient funds to repay her debt. If the downstream party refuses to repay $\left(1+r_{t}\right) D_{t}$ and instead defaults, its business is liquidated at the end of period $t$. The downstream party is protected by limited liability, so creditors do not receive any repayment given the downstream party defaults. ${ }^{6}$

Anticipating later results deriving indirect costs of debt financing, the downstream firm would be on the safe side using no debt at all. However, it might want to use debt for reasons not worked out in our benchmark model. For example, profits might be taxed and interest payments are usually tax-deductible, which would reduce the effective cost associated with debt financing (see Appendix II, Section 6). Furthermore, internal funds might not be sufficient to finance $I$, and external equity associated with agency costs (see Fahn et al., 2017).

\subsubsection{Contractability}

We first describe our assumptions on contractability, and discuss some of them in the next section.

In every period, the downstream party makes a contract offer to the upstream party. This contract involves an ex-ante payment $w_{t}$ and a price $P_{t}$ to be paid upon delivery, as well as the quality level $q_{t}$. $w_{t}$ and $P_{t}$ can assume negative values, indicating payment streams from upstream to downstream party. In the following, we focus on contracts that prescribe delivery of high quality. The parties can use formal spot contracts or relational contracts (or a combination of both) to enforce their agreement. The latter are self-enforcing implicit arrangements which are further described below.

\footnotetext{
${ }^{6}$ The possibility of creditors taking over after a default and continuing to run the downstream party's business would not affect our results, as long as the original downstream party fully loses access to its original business.
} 
Formal enforcement is costly, and is carried out by a court which is able to determine the quality of the intermediate good and whether contractually specified payments have been made. Assume that the downstream party withholds payment of the price and claims that quality is low. If quality has actually been high, the upstream party can sue the downstream party, in which case it wins with probability 1 and is subsequently awarded $P$, but has to bear (net) enforcement cost $K>0$. The litigation value enforced by a court cannot exceed $\theta$, the value the intermediate good has for the downstream party. Hence, courts only enforce prices $P \leq \theta$.

Being sued and losing a trial is also costly for the downstream party. We do not have to specify the exact amount of the downstream party's cost when losing a trial, though, since those do not affect any player's optimal behavior. If the upstream party refuses to deliver high quality, we assume, without loss, that it just does not receive $P$.

The downstream party can keep the intermediate good in any case, even after refusing to pay the price $P$ and not being sued by the upstream party afterwards.

Finally, creditors cannot detect the quality of the intermediate good and whether the downstream party agrees to pay $P$, but find out whenever the upstream party sues the downstream party and then observe the outcome of the verdict. To simplify the analysis, we assume that all aspects of the relationship between downstream party and creditors (as further defined below) are detected by the whole credit market. This allows us to assume without loss of generality that the principal only borrows from one creditor.

Discussion of Contractability Assumptions Our specification of formal contracting follows the description of the above mentioned hypothetical case behind the measure of contract enforcing costs we use in our empirical analysis. This measure considers costs that must be advanced by the upstream party when filing the lawsuit, no matter whether those are reimbursed or not. In our model, however, $K$ must be borne by the upstream party, even if it wins the lawsuit. Hence, these costs are net of expenses that potentially are reimbursed by the downstream party after a positive court decision.

We think that legal expenses that must be advanced by the upstream party are a good proxy for its final expenses, for the following reasons. First, whether the loser of a trial has to bear the other party's legal costs or not varies across jurisdictions. ${ }^{7}$ Second, higher costs that must be advanced by the upstream party should generally translate

\footnotetext{
${ }^{7}$ In our empirical analysis we take this variation into account by controlling for the existence of a so-called "loser-pays-rule".
} 
into higher costs that must finally be borne by the upstream party even if a "loserpays-rule" exists. Although we assume that the upstream party wins with probability 1 (following the hypothetical case described in the empirical section), in reality there will always be some uncertainty. Therefore, even if it is reimbursed for its expenses after a victory, the upstream party will in some cases still have to bear those costs. Furthermore, since the maximum litigation value is $\theta$ (an aspect we are going to discuss in the next paragraph), it is not possible to arbitrarily adjust the contracted price $P$ upward in order to fully internalize any expected costs.

We restrict the litigation value by $\theta$, the maximum price that is enforced by a court. The exact upper bound of court-enforceable prices is not relevant, as long as there is one - and $\theta$ seems like a natural value. If there was no upper bound on courtenforceable prices, enforcement cost $K$ would become irrelevant (by setting $P$ very high and making up for it with a low negative ex-ante payment $w$ ). Furthermore, no additional "liquidated damages" which the party breaching the contract must pay to the other party are enforced.

These restrictions on the contracting space can be justified by two aspects. First, courts usually do not enforce liquidated damages that appear excessive relative to actual damages. In other words, if a liquidated damage appears to be rather a penalty for contract-breach, it is generally turned down by courts (see Farnsworth, 2004, or Posner, 2011). Second, a high ex-post payment would only be optimal for the downstream party if it was accompanied by a low negative ex-ante payment. If we assumed a limited liability constraint on the upstream party's side, though, this option would not be available. Such a limited liability constraint would only slightly affect our results, however complicate the analysis. To keep it simple, we assume instead that enforceable prices are bounded.

Finally, we assume that the downstream party can keep the intermediate good in any case, even after refusing to pay the price $P$ and not being sued by the upstream party afterwards. This assumption can be endogenized by introducing an additional bargaining stage over ownership of the good after the downstream party refused to pay the contractual price $P$. Because the outside value of the intermediate good is zero, the upstream party would accept any positive offer by the downstream party. 


\subsubsection{Equilibrium}

The equilibrium concept we apply is subgame-perfect equilibrium. Respective strategies maximize a player's discounted payoff stream, given other players' strategies. There, we do not treat creditors as full players but assume that those are willing to lend at conditions where they do not expect losses, taking equilibrium play as given. Without loss of generality, we confine our interest to stationary contracts. Hence, on the equilibrium path, quality $q$, payments $w$ and $P$, and debt level $D$ are the same in every period $t$. This allows us to omit time subscripts.

In the following, our objective is to characterize a stationary subgame-perfect equilibrium that maximizes the firm's expected discounted profit stream in period $t=0$.

\subsubsection{Payoffs}

The downstream party's per-period payoff in an equilibrium where it pays the price $P$ is $\pi=q \cdot \theta-w-P-(1+r) D+D$. The upstream party's per-period payoff in this case amounts to $u=w+P-q \cdot c$. Both players are assumed to have outside options of zero, and the downstream party's discounted payoff stream in any period $t \geq 1$, given high quality is provided, equals

$$
\Pi=\frac{\theta-w-P-r D}{1-\delta}
$$

In period $t=0$, the first period in which investment $I$ must be made, the downstream party's payoff stream is

$$
\Pi_{0}=-(I-D)+\delta \Pi \text {. }
$$

Finally, the upstream party's discounted payoff stream in any period $t \geq 1$, given high quality is provided, equals

$$
U=\frac{w+P-c}{1-\delta}
$$

\subsection{Arrangement Between Downstream and Upstream Party}

The downstream party has two arrangements, one with the upstream party and (potentially) one with a creditor. In this section, we focus on the former and analyze the different forms of downstream-upstream relationships. We assume that on the equilibrium path, defaulting on debt is never optimal for the downstream party and derive 
the respective conditions for this to hold in the subsequent section.

The arrangement between downstream and upstream party determines payments $w$ and $P$. It also determines that the intermediate good ought to be of high quality in every period. The downstream party is supposed to pay $P$ at the end of a period if quality is high, but still might be tempted to refuse payment. Therefore, it is crucial to identify if and how the payment $P$ can actually be enforced. Potential mechanisms are formal, court-enforceable contracts, relational contracts, or a combination of those two.

Before exploring this aspect, note that irrespective of which enforcement mechanism is used, it must be optimal for the upstream party to enter the arrangement in every period and provide high quality. The first aspect is taken care of by an individual rationality (IR) constraint. Generally, this constraint amounts to

$$
w+P-c \geq 0
$$

Note that when relational contracts are used, an (IR) constraint equals $U \geq 0$, which is, however, identical to $w+P-c \geq 0$, given the stationarity of the game.

After signing the contract, it must be in the upstream party's interest to deliver high quality (provided it expects subsequent payment of $P$ ), which is captured by the incentive compatibility (IC) constraint. Generally, this constraint amounts to

$$
P \geq c
$$

Note that when relational contracts are used, an (IC) constraint equals $-c+P+\delta U \geq$ 0 or $-c+P+\delta w \geq 0$. It turns out, though, that setting $w=0$ is (weakly) optimal in the relational contract, and hence, (IC) constraints also are equivalent in all regimes.

In the next sections, we derive conditions for the enforceability of $P$, analyzing the potential enforcement mechanisms separately.

\subsubsection{Formal Spot Contracts}

The parties might rely on formal spot contracts in order to enforce $P$. For those to work, it must be optimal for the upstream party to sue the downstream party in case high quality has been provided but the latter refused to pay $P$. Since the upstream party receives the agreed-upon price $P$ after a positive verdict, this requires $K \leq P$. Moreover, enforceable price levels are restricted to amounts below $\theta$. This implies that 
high quality can only be enforced in a spot contract for cost levels

$$
K(\leq P) \leq \theta
$$

If this condition holds, the following contract (not uniquely) maximizes the downstream party's profits. $P+w=c$, i.e. the (IR) constraint binds, and the upstream party does not receive a rent. $K \leq c$ implies $P=c$ and $w=0 ; c<K \leq \theta$ implies $P=K$ and $w=c-P$. In the first case, costs of enforcing contracts are so low that the upstream party will sue the downstream party in any case. In the second case, costs of enforcing contracts are relatively high such that a higher price is determined in order to make it optimal for the upstream party to sue the downstream party in case the latter refused to pay $P$. Then, the ex-ante payment $w$ is negative.

If enforcement costs are above $\theta$, formal spot contracts cannot be used to generate high quality. In this case, the maximum enforceable price $P$ would be below $K$, and the upstream party would not sue the downstream party. Hence, the latter would refuse to pay $P$ after delivery of the intermediate good - and the upstream party not produce high quality in the first place.

Note that given $K \leq \theta$ and formal spot contracts are feasible, the downstream party never refuses to pay $P$ on the equilibrium path, and the costs $K$ never materialize. Then, efficiency is obtained in the relationship between upstream and downstream party, and the latter party can reap the full surplus. Therefore, it is (weakly) optimal to use formal spot contracts whenever feasible.

\subsubsection{Relational Contracts}

Assume that $K>\theta$, so that downstream and upstream party cannot use spot contracts. Still, they might form a relational contract, where the downstream party makes the promise to not withhold the payment of $P$ after high quality has been delivered. In this section, we derive conditions for a "pure" relational contract to work, and assess potential combinations in the following section. The downstream party's promise to pay $P$ has to be credible, which is the case if paying $P$ gives the downstream party a higher continuation payoff than refusing to do so. Put differently, if it reneges and withholds payment of $P$, the downstream party's continuation payoff must be sufficiently reduced. We assume that a deviation by the downstream party triggers a reversion to the static 
Nash equilibrium, in which high quality can subsequently not be enforced anymore. ${ }^{8}$ Therefore, if it reneges, the downstream party will subsequently also default on its debt. 9 The downstream party's dynamic enforcement (DE) constraint determines the extent to which payment of $P$ can be enforced within a relational contract and equals

$$
-P-(1+r) D+D+\delta \Pi \geq 0
$$

Using $\Pi=\frac{\theta-P-w-r D}{1-\delta}$, the (DE) constraint becomes $-P-r D+\delta(\theta-w) \geq 0$.

Since we are interested in an arrangement that maximizes the downstream party's profits, $w=0$ and $P=c$.

\subsubsection{Formal Enforcement in Long-Term Arrangement}

Even if $K>\theta$, players can potentially make use of formal contracts, with the following long-term arrangement: In case the downstream party refuses to pay $P$ despite the delivery of high quality, the upstream party sues the downstream party and is subsequently awarded $P$. Afterwards, the relationship continues, but continuation play is adjusted such that the upstream party's continuation profits are large enough to make up for the difference $K-\theta$. Denoting the upstream party's off-path profits by $\tilde{U}$, the condition making it optimal for the upstream party to sue the downstream party then equals

$$
\theta-K+\delta \tilde{U} \geq 0
$$

There, we take into account that it is optimal to set $P$ as high as possible, i.e., $P=\theta$, which implies $w=c-P$.

For this arrangement to work, a number of further constraints must hold off the equilibrium path; in particular, also the downstream party's off-path continuation profits must be large enough that it still repays debt and does not default. We pin down those constraints formally in the proof to Proposition 1. Finally, note that a dynamic enforcement constraint is not required because payment of $P$ is ultimately enforced by a court.

\footnotetext{
${ }^{8}$ This is optimal since Abreu (1988) shows that a player with an observable deviation from equilibrium behavior should optimally be punished by receiving their minmax-payoff.

${ }^{9}$ Note that the downstream party might also repay the loan and enter the credit market again in the subsequent period - trying to borrow more than before and then default on this larger amount. Such a devation from the downstream party's equilibrium borrowing behavior, though, would let creditors conclude that the downstream party has reneged.
} 


\subsection{Maximum Debt}

Let us now analyze the downstream party's decision on how to finance the initial investment $I$. There, we do not solve for a uniquely optimal debt level, but rather derive the maximum amount of debt it can possibly use. Within our model setup, it will turn out to be weakly optimal for the downstream firm to only use (internal) equity financing (on which we impose no restrictions). But there are many reasons outside our model for why firms might use debt, for example because of associated tax benefits (which we analyze in Appendix II, in Section 6), or because they do not have sufficient internal funds and using external equity triggers agency costs (see Fahn et al., 2017). In these cases, the maximum debt level that we derive below is equivalent to the uniquely optimal debt level. In the following, we abstract from those aspects in order to isolate implicit costs of debt financing, and predict that firms facing a lower maximum debt threshold should ultimately also use less debt.

Because the credit market is competitive, the interest rate $r$ is determined by $-D+$ $\delta(1+r) D=0$ and equals $r=(1-\delta) / \delta$. Then, the downstream party's profits at the beginning of the game, $\Pi_{0}=-(I-D)+\delta \Pi=-I+\delta \frac{\theta-c}{1-\delta}$, are independent of the financing structure. This is because downstream party and creditor share the same discount factor, hence the direct costs of using debt or equity financing are identical. But debt affects the downstream party's incentives. It is protected by limited liability and might for this reason be tempted to default in order to save on interest payments today - at the expense of future profits. Therefore, debt must be sufficiently small such that a default is not optimal, which is captured by the downstream party's no-default (ND) condition,

$$
-r D+\delta \Pi \geq 0 .
$$

This condition must hold irrespective of the kind of arrangement upstream and downstream party use to govern their relationship. However, only if formal spot contracts are used, the (ND) constraint actually is relevant. With relational contracts or formal enforcement in a long-term arrangement, debt is restricted by even tighter constraints. Then, the downstream party's debt level also affects the interaction between upstream and downstream party.

First, the dynamic enforcement constraint for a relational contract equals $-P-r D+$ $\delta \Pi \geq 0$, which is tighter than (ND). Second, with formal enforcement in a long-term arrangement, a no-default condition also must hold off the equilibrium path. In case the 
downstream party refused to pay $P$ and is sued by the upstream party, the downstream party subsequently cannot keep the full surplus of the continuation game. Instead, it has to grant the upstream party a share that is sufficient to cover the difference $K-\theta$. Denoting the downstream party's off-path profits by $\tilde{\Pi}$, her off-path no-default constraint becomes $-r D+\delta \tilde{\Pi} \geq 0$. Since $\tilde{\Pi}<\Pi$, this constraint is tighter than (ND).

Finally, because the regime to enforce high effort depends on the costs of enforcing formal contracts, $K$, also the maximum debt threshold is a function of $K$. This relationship is made precise in Proposition 1:

Proposition 1 In an equilibrium where high quality is provided in every period and the downstream party never defaults on the equilibrium path, the downstream party's maximum debt $\bar{D}$ is characterized by

- $\bar{D}^{S C}=\delta^{2} \frac{\theta-c}{1-\delta}$ for $K \leq \theta$,

- $\bar{D}^{L C}=\delta^{2} \frac{\theta-c}{1-\delta}-\delta(K-\theta)$ for $\theta<K \leq \theta+c$,

- $\bar{D}^{R C}=\delta^{2} \frac{\left(\theta-\frac{c}{\delta}\right)}{1-\delta}$ for $K>\theta+c$,

with $\bar{D}^{R C}<\bar{D}^{L C}<\bar{D}^{S C}$.

The proof to Proposition 1 can be found in Appendix I.

The maximum debt threshold for a formal spot contract, $\bar{D}^{S C}$, directly follows from the downstream party's (ND) constraint: Debt reduces future profits because of required interest payments. If these payments are too high compared to discounted future profits, the downstream party rather sacrifices the latter and defaults. Since formal spot contracts are only feasible for relatively low enforcement costs $K, \bar{D}^{S C}$ is the effective maximum-debt threshold in this case.

$\bar{D}^{R C}$ follows from the downstream party's (DE) constraint. It is smaller than $\bar{D}^{S C}$ because of a direct interaction of the downstream party's relationships with creditor and upstream party. The downstream party's commitment in each relationship is given by the difference between its future on- and off-path rents. Interest payments on debt reduce future on-path rents without affecting off-path rents, as the downstream party also defaults after reneging on the relational contract. Therefore, debt allows the downstream party to share its costs of reneging with the creditor.

Formal enforcement in a long-term arrangement is an intermediate case. It only works if the productive relationship continues after the downstream party refused to 
pay $P$ and is subsequently sued, because the upstream party is only willing to sue the downstream party if it receives a share of the continuation surplus. This reduces the downstream party's off-path rents and therefore increases its temptation to default after being sued.

If enforcement costs are only slightly above $\theta$, formal enforcement in long-term arrangements is, ceteris paribus, easier to enforce than relational contracts, because the increase in the downstream party's off-path default temptation is only moderate. The benefits provided by formal enforcement then outweigh the increased default temptation. If enforcement costs are rather large, however, the off-path rent that has to be given to the upstream party is so large that the players rather forego the benefits of formal enforcement and use relational contracts.

\subsubsection{Comparison and Main Empirical Prediction}

We predict that firms facing a higher maximum debt threshold should generally also use more debt, because benefits of debt such as tax-deductibility (as we analyze in Appendix II) would make those maximum debt levels uniquely optimal. Proposition 1 relates the downstream party's maximum debt threshold to the cost of enforcing formal contracts. It states that the maximum debt threshold is decreasing in enforcement costs $K$.

Now, let us assume several countries with many different relationships of upstream and downstream firms, but one value of $K$ for each country. Following our theoretical analysis, one would expect formal long-term arrangements and relational contracts to be used more widely in countries with larger costs $K$, a conclusion also supported by Besley (2015). ${ }^{10}$ This - together with Proposition 1 - yields our main empirical prediction.

Empirical Prediction 1: The higher the costs of enforcing formal contracts in a country, the lower are the debt ratios of firms.

\footnotetext{
${ }^{10}$ Besley (2015) states that a "robust finding in the Doing Business report is that the countries which have a higher rank tend to have smaller informal sectors. This pattern suggests that the choice to become a formal firm may be a key margin affected by business regulation and formal laws [...]. But for that very reason, the way in which business conditions affect the extensive margin between whether firms choose to be formal and informal may be more important than how such rules affect the behavior of the formal sector taken alone." (Besley, 2015, p. 107).
} 


\section{Empirical Analysis}

\subsection{Econometric Approach}

We test our main empirical prediction by estimating the effect of contract enforcement costs on external debt financing using firm-level panel data. Since we express our outcome variable as the fraction of debt in total financing capital, our econometric approach needs to account for the bounded nature of it. To do so we apply a panel data fractional response model as proposed by Papke and Wooldridge (2008). This method is particularly appealing, since it accommodates unobserved firm heterogeneity. We estimate the model for our sample of $i=1, \ldots, N$ firms which we observe over time $t=1, \ldots, T$. The choice variable in our analysis is the share of external debt $d_{i t}$, with $0 \leq d_{i t} \leq 1$. Note that the outcomes 0 and 1 are specifically allowed for (Papke and Wooldridge, 2008). ${ }^{11}$

The functional form assumption conditional on explanatory variables $\mathbf{x}_{i t}$ is given by

$$
E\left(d_{i t} \mid \mathbf{x}_{i t}, c_{i}\right)=\Phi\left(\mathbf{x}_{i t} \boldsymbol{\beta}+c_{i}\right), \quad t=1, \ldots, T
$$

The $1 \times K$ vector of explanatory variables $\mathbf{x}_{i t}$ includes firm- industry- and countrylevel determinants of debt shares. ${ }^{12}$ In particular, it includes $C O E C_{j t}$, our measure of contract enforcing costs in country $j$ and year $t$, along with a number of standard control variables that have been identified by previous literature to explain debt shares. $\Phi($. refers to the standard normal cdf, and $c_{i}$ is a time-constant firm-specific unobserved effect. The vector of explanatory variables $\mathbf{x}_{i t}$ is assumed to be strictly exogenous conditional on $c_{i}$. Following Chamberlain (1980), the unobserved effect $c_{i}$ is assumed to be normally distributed, conditional on $\mathbf{x}_{i t}$ :

$$
c_{i}=\psi+\overline{\mathbf{x}}_{i} \boldsymbol{\xi}+a_{i}, \quad \text { with } \quad a_{i} \mid \mathbf{x}_{i} \sim \operatorname{Normal}\left(0, \sigma_{a}^{2}\right)
$$

where $\overline{\mathbf{x}}_{i} \equiv T^{-1} \sum_{t=1}^{T} \mathbf{x}_{i t}$ is a $1 \times K$ vector of time averages. The elements of $\boldsymbol{\beta}$ are shown to be identified up to a positive scale factor

$$
E\left(d_{i t} \mid \mathbf{x}_{i t}\right)=\Phi\left[\left(\psi+\mathbf{x}_{i t} \boldsymbol{\beta}+\overline{\mathbf{x}}_{i} \boldsymbol{\xi}\right) /\left(1+\sigma_{a}^{2}\right)^{1 / 2}\right]=\Phi\left(\psi_{a}+\mathbf{x}_{i t} \boldsymbol{\beta}_{a}+\overline{\mathbf{x}}_{i} \boldsymbol{\xi}_{a}\right) .
$$

\footnotetext{
${ }^{11}$ In our data, however, 0 s and $1 \mathrm{~s}$ are not very frequently observed. To be precise, of 167,503 observations, 2,165 and 15 exhibit the values 0 and 1 , respectively.

${ }^{12}$ To simplify notation, we omit industry and country indices in the formal representation of the econometric model.
} 
The scaled coefficients can be estimated by pooled quasi maximum likelihood estimation (QMLE). Once we have estimated $\boldsymbol{\beta}_{a}, \psi_{a}$, and $\boldsymbol{\xi}_{a}$, we can estimate an Average Partial Effects (APEs) by differencing the average structural function

$$
E_{\overline{\mathbf{x}}_{i}}\left[\Phi\left(\psi_{a}+\mathbf{x}_{i t} \boldsymbol{\beta}_{a}+\overline{\mathbf{x}}_{i} \boldsymbol{\xi}_{a}\right)\right]
$$

which is consistently estimated by

$$
N^{-1} \sum_{i=1}^{N} \Phi\left(\psi_{a}+\mathbf{x}_{i t} \boldsymbol{\beta}_{a}+\overline{\mathbf{x}}_{i} \boldsymbol{\xi}_{a}\right) .
$$

Hence, the APE of $C O E C_{j t}$ on $E\left(d_{i t} \mid \mathbf{x}_{i t}, c_{i}\right)$ is estimated as

$$
\beta_{C O E C} \cdot N^{-1} \sum_{i=1}^{N} \phi\left(\psi_{a}+\mathbf{x}_{i t} \boldsymbol{\beta}_{a}+\overline{\mathbf{x}}_{i} \boldsymbol{\xi}_{a}\right)
$$

\subsection{Determinants of Debt Shares}

Apart from our variable of interest, 'cost to enforce a formal contract' $\left(C O E C_{j t}\right), \mathbf{x}_{i t}$ includes important firm-, industry-, and country-specific determinants of a firm's debt share. Let us start by presenting the variables which are measured at the firm level. The log of sales is included to control for firm characteristics such as its size. As larger firms are expected to face lower bankruptcy probabilities, we expect the sales to be positively related to external debt financing (e.g., Graham and Harvey 2001; Frank and Goyal, 2009). We further control for whether a firm carries forward any losses in a given year. The variable is related to tax incentives faced by a firm. If losses have been carried forward from past financial years, tax savings associated with debt and interest deductions are zero, and we expect a negative effect on external debt financing (see, e.g., MacKie-Mason, 1990). If carrying forward losses captures liquidity problems and the firm cannot retain earnings, the variable may also have a positive impact. We include the share of tangible assets relative to total assets. On the one hand, higher values thereof might crowd out tax benefits of debt because non-debt tax shields associated with tangible assets (like depreciation allowances) may substitute for interest deductions (see De Angelo and Masulis, 1980). On the other hand, if more tangible assets are associated with more collateral, facilitating borrowing, the impact of this variable may be positive (see Rajan and Zingales, 1995; Huizinga, Laeven and Nicodème, 2008). 
As a measure of risk we include the standard deviation of sales in a firm's sector in a given year. ${ }^{13}$ This variable measures the volatility of cash flows. Firms in industries where high values of risk are observed should face higher expected costs of financial distress, and this should lead to less debt financing (see Frank and Goyal, 2009). ${ }^{14}$

Since firms are located in different host countries, we additionally include countryspecific characteristics. Similar country controls have been chosen in the studies of Desai, Foley, and Hines (2004), and Buettner, Overesch, Schreiber, and Wamser (2009). An important incentive to use debt instead of equity financing is a country's statutory tax rate. The tax rate on corporate profits captures the marginal tax incentive for using external debt financing (Desai, Foley, and Hines, 2004; or Buettner, Overesch, Schreiber, and Wamser, 2009). An increase in the tax rate should positively relate to external debt as the value of interest deductions associated with debt increases in the tax rate. As a measure for market growth we include the annual growth of a country's GDP, which may very generally capture the economic situation of a country. If growth today is a good indicator for future growth, then the effect on external debt should be positive (Harris and Raviv, 1991). However, Graham and Leary (2012) argue that high market-to-book ratios - indicating good growth options - should be negatively related to leverage, because of debt overhang concerns (see Myers, 1977). ${ }^{15}$ This argument suggests a negative effect of GDP growth on debt shares. Another explanation for a negative GDP growth effect is that high growth may allow firms to issue more equity.

Given our interest in isolating the effect of contract enforcement costs, we need to control for other institutional aspects that might determine debt financing and which are likely to be correlated with our measure of contract enforcement costs. We include an index on the depth of credit information which is determined by a country's rules affecting the scope, accessibility, and quality of credit information available through public or private credit registries. To capture differences in corruption across locations, we include a measure for freedom from corruption. Corruption has been found to positively affect external debt (for this argument, see Kesternich and Schnitzer, 2010; or Desai, Foley, Hines, 2008). To measure the quality of the local capital market, we include domestic credit provided by the banking sector relative to GDP and a measure for financial freedom. Additional aspects of the local credit market should be captured by the inflation rate.

\footnotetext{
${ }^{13}$ According to the MiDi industry classification, firms in our sample operate in 30 different industries.

${ }^{14}$ We will discuss the impact of risk in the context of our model below.

${ }^{15}$ See also Rajan and Zingales (1995), as well as Myers (2001).
} 
Table 1 provides a list of all determinants of debt shares included in our analysis as well as their sources. Finally, note that all estimations in Section 4.4 additionally condition on unobserved, time-constant, firm-heterogeneity, as well as aggregate time effects; the firm-specific effects nest country- as well as industry-effects. ${ }^{16}$

\section{- INCLUDE TABLE 1: VARIABLES -}

\subsection{Data}

Our empirical analysis is based on firm-level data from the Microdatabase Direct Investment (MIDi) provided by Deutsche Bundesbank (the German Central Bank). This dataset includes almost all foreign activities of German multinational firms (MNFs), as foreign transactions are subject to legal reporting requirements whenever the foreign activity of a German firm is above a given reporting threshold. Using MiDi for the purpose of this paper has two main advantages. One advantage is that, given the reporting requirements mentioned above, MiDi virtually includes the universe of German multinationals. ${ }^{17}$ More importantly, the data provide information on external debt (provided by external creditors) as well as equity capital, allowing us to determine an external-debt-to-capital ratio for each independent foreign entity. As internal debt financing (provided internally from affiliated entities or the parent firm) is in many aspects - though not all, of course - similar to equity financing, we think that the ability to distinguish between external and internal debt is crucial.

Table 2 reports descriptive statistics on all variables. After excluding all financial services and holding entities, our data includes 33,583 firms held by 7,965 German investors in 124 countries. ${ }^{18}$ Overall, our panel data analysis is based on 167,503 observations. The dataset is unbalanced, but the number of observations over the 9 years covered (2004 to 2012 ) is relatively stable. ${ }^{19}$

\section{- INCLUDE TABLE 2: DESCRIPTIVE STATISTICS -}

\footnotetext{
${ }^{16}$ Other papers of capital structure choice often condition on the so-called $z-$ score. Apart from endogeneity concerns, we do not have enough information in our data to calculate this measure.

${ }^{17}$ Reporting thresholds are very low. A 'brief guide' (Lipponer, 2007) about MiDi, including details on reporting thresholds, is available online.

${ }^{18}$ Financial services and holdings are excluded since it is well know that the capital structure choice of these firms is not comparable to the one of other firms; for example, with respect to tax treatment and regulation.

${ }^{19}$ Note that, while the micro information from MiDi goes back until 1999, our explanatory variable of interest is only available from 2004 on.
} 
The endogenous variable in our empirical analysis is the external-debt-to-totalcapital ratio of firm $i$ in year $t$ (denoted by $d_{i t}$ ). The grand mean of this variable over all 167,503 observations is 0.329 ; over time, the yearly average goes down by almost 5 percentage points from 0.350 (in 2004) to 0.305 (in 2012)..$^{20}$

To measure the costs of enforcing a contract, we make use of the World Bank's Doing Business database. As mentioned earlier, we focus on the variable 'cost to enforce a contract (in \% of claim)' at the location of firm $i$ at time $t\left(C O E C_{j t}\right)$. This measure is obtained by computing the cost of a hypothetical case of a commercial legal dispute between a seller and a buyer. ${ }^{21}$ The dispute arises from the buyer's refusal to pay for a delivered customized good because of inadequate quality. The seller sues the buyer referring to their sales agreement. An expert witness is called, the judge confirms that the goods are of adequate quality, and the final judgment is in favor of the seller. The buyer must pay. The variable provided in the Doing Business database measures costs related to such a case including court costs, enforcement costs, and average attorney fees. In its Doing Business report, the World Bank provides examples on reforms that have affected the costs of enforcing a contract in selected countries. For example, the World Bank reports that China increased the procedural efficiency at the main trial court in 2012 and particularly "made enforcing contracts easier by amending its Code of Civil Procedure to streamline and expedite court proceedings". In the same year, Côte d'Ivoire created a specialized commercial court that brought along reductions in the costs of enforcing a contract. ${ }^{22}$ We provide more examples of changes in the cost of enforcing contract variable in the Appendix to this paper. The unconditional correlation between the two central variables of our study, $C O E C_{j t}$ and $d_{i t}$, is -0.0172 .

\subsection{Basic Results}

Table 3 presents the results of the fractional response model. All estimations condition on firm-specific effects as well as on aggregate year effects (using the estimation approach outlined above). Column 1 of the table shows the estimated coefficients (and standard errors), column 2 presents the average partial effects (APEs).

The central result for our paper is the finding of a negative effect of $C O E C_{j t}$. Our

\footnotetext{
${ }^{20}$ More details on the measurement of variables is provided in Section 4.2.

${ }^{21}$ See http://www.doingbusiness.org/methodology/enforcing-contracts, for more details on how the hypothetical case is constructed.

${ }^{22}$ The World Bank's yearly Doing Business reports provide a large number of examples on how countries affected the costs of enforcing a contract by implementing institutional reform.
} 
estimates suggest an average partial effect (APE) of $C O E C_{j t}$ equal to -0.0011 . To quantitatively interpret this coefficient, let us consider a discrete jump in $C O E C_{j t}$ by one standard deviation (11.15) from its mean value of 22.53 to 33.68. The suggested decrease in the external debt ratio, given the discrete jump, then equals 0.0127 (or 1.27 percentage points). We will quantify the impact of $C O E C_{j t}$ in a number of quantification experiments in Section 4.6.

The coefficients of the control variables are estimated with the expected signs (see the previous section). The positive impact of sales indicates that larger firms may have better access to debt. Firms with losses carried forward may not be able to retain earnings, which would explain the positive effect of Losscarryforward $_{i t}$. The third firm-level control, Tangibility $y_{i t}$, is positive but not statistically significantly related to the external-debt-to-capital ratio.

An increase in Risk $_{s t}$ has a negative effect on external debt. In Section 4.5.3 we will test features of our theory by examining whether the sensitivity of the capital structure with respect to the cost-to-enforce-a-contract variable depends on Risk $_{s t}$ (we will therefore come back to this variable below).

The deduction of interest cost is one of the main benefits of using debt instead of equity. This suggests that borrowing provides for a tax shield and the statutory tax rate should be positively related to external debt. The APE of 0.066 means that a firm increases its external-debt-to-capital ratio by about 0.7 percentage points in response to a 10 percentage point higher tax.

A higher value of the credit information index leads to less external debt financing,

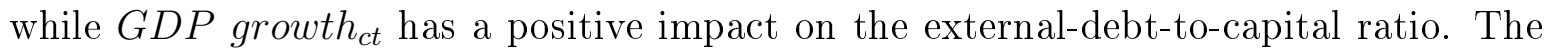
latter suggests that new investments in a growing economy are often debt financed.

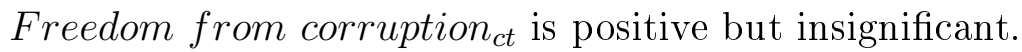

From the three variables included to measure capital market conditions, only Domestic $_{\text {credit }}$ ct has a statistically significant effect and affects the external debt ratio negatively. This might indicate that MNFs have access to external debt financing, even though they face an underdeveloped local capital market. Yet, as the variable is a very general indicator for the quality of a local capital market, it is not clear if higher values thereof are associated with facilitated access to equity capital. ${ }^{23}$

\section{- INCLUDE TABLE 3: BASIC RESULTS -}

\footnotetext{
${ }^{23}$ Note that we will present results below, where we omit these three variables.
} 


\subsection{Additional Results and Robustness}

\subsubsection{Measurement Issues}

The purpose of this section is to show that $C O E C_{j t}$ is well identified. Note that $C O E C_{j t}$ varies over time to a significant extent. This is important as our estimation approach focuses on time variation and conditions on time-constant firm-i-specific heterogeneity. Table A1 in the Appendix shows examples of reforms that led to changes in the cost to enforce a contract. Table 4 presents estimated coefficients and APEs for two additional tests. First, columns 1 and 2 report results for the fractional response model where all capital market variables (Domestic credit $_{j t}$, Financial freedom $_{j t}$, Inflation rate I $_{j t}$ ) are excluded. If we are concerned that $C O E C_{j t}$ mainly picks up variation of capital market characteristics, excluding those variables should affect the estimate of $C O E C_{j t}$. Table 4 shows that this is not the case and the results are hardly affected when the three variables are excluded.

As countries differ significantly in $C O E C_{j t}$ (the variable varies from about 7 to 150), our estimates may be sensitive to using the $\log$ of $C O E C_{j t}$ instead of its level. Columns 3 and 4 suggest that this is not the case by confirming the finding of a negative relationship. ${ }^{24}$ As the 'cost to enforce a contract' is measured 'in \% of claim', we prefer the level variable as it allows for interesting quantifications (see Section 4.6).

\section{- INCLUDE TABLE 4: MEASUREMENT ISSUES -}

\subsubsection{Loser-Pays Rule}

Our model is based on a hypothetical case of a legal dispute between upstream party and downstream party which is used to determine the variable $C O E C$. This case is constructed assuming that the costs of enforcing contracts have to be advanced by the upstream party when filing the lawsuit, irrespective of whether those are reimbursed or not. We have argued that even if those are reimbursed, the costs $K$ affect the upstream party's decision because, effectively, it cannot be sure to win a lawsuit with probability 1 and because the amount it is alloted to is restricted to values below $\theta$. Furthermore, some parts or dimensions of the enforcement costs might not be reimbursed. Still, the upstream party should be less affected by the cost of enforcing a formal contract if it can generally reclaim a major part of its expenses after winning the lawsuit. We therefore make use of the fact that a so-called "loser-pays rule" exists in some countries but not

\footnotetext{
${ }^{24}$ Note that our sample does not include too many observations where $C O E C_{j t}$ is larger than 50 .
} 
in others. Such a rule states that the loser of a lawsuit must also cover the winner's legal expenses.

Empirical Prediction 2: The effect of costs of enforcing formal contracts on debt financing should be less pronounced if a loser-pays rule is in place.

In the following, we borrow from Djankov et al. (2003) who have collected a vast amount of legal data for numerous countries - including whether the aforementioned loser-pays rule exists -, and use this variable for our analysis. In Table 5, we additionally condition on an interaction term between the cost of enforcing contract variable and the existence of a loser-pays rule (columns 1 and 2). In particular, we use the binary loser-pays variable $L O S E R P A Y S_{j}$, which equals one if the country where the firm locates has established a loser-pays rule, and zero if no such rule exists. Note that $L O S E R P A Y S_{j}$ does not enter the estimation as a separate variable as it does not exhibit variation over time. As expected, the marginal impact of $C O E C_{j t}$ becomes smaller if such a rule exists (less negative). Columns 3 and 4 focus only on countries where $L O S E R P A Y S=0$ and confirms the negative (slightly larger) effect of $C O E C_{j t}$.

\section{- INCLUDE TABLE 5: LOSER-PAYS RULE -}

\subsubsection{Risk}

In the corporate finance literature, exposure to risk is regarded as an important factor determining a firm's optimal capital structure, and has therefore been included as a control variable in our empirical analysis. Although we do not explicty incorporate risk into our model, we can take the size of the discount factor $\delta$ as a proxy for the riskiness of a firm's environment. It is a common perception that the discount factor in dynamic games does not only represent pure time preferences, but can also capture the probability with which the game continues for another period. If we assume that a riskier environment is generally associated with a higher (not further modelled) risk

of going bankrupt, we would expect that such a riskier environment is represented by a lower discount factor. This allows us to generate an empirical prediction.

Empirical Prediction 3: Firms should have less debt in a riskier environment. 
Proof. This immediately follows from taking the derivative of the downstream party's debt threshold with respect to the discount factor: $d \bar{D}^{R C} / d \delta>0, d \bar{D}^{L C} / d \delta>0$ and $d \bar{D}^{S C} / d \delta>0$. Hence, more risk (i.e., a lower discount factor) reduces a firm's maximum debt threshold.

Prediction 3 has already been confirmed by our empirical analysis since the coefficient for risk shows a negative sign (see Table 2).

Furthermore, we can derive a prediction that is specific to our model:

Empirical Prediction 4: The effect of costs of enforcing formal contracts on debt financing should be less pronounced in a riskier environment.

Proof. The maximum debt threshold is a continuous function of $K$. Its respective value is given by $\bar{D}^{S C}$ for $K \leq \theta, \bar{D}^{L C}$ for $\theta<K \leq \theta+c$, and $\bar{D}^{R C} K>\theta+$ c. There, only $\bar{D}^{L C}=\delta^{2} \frac{\theta-c}{1-\delta}-\delta(K-\theta)$ directly contains $K$, with $\frac{d^{2} \bar{D}^{L C}}{d \delta d K}=-1$. This confirms Prediction 4 since the effect of $K$ on debt is less negative if risk is higher (i.e. the discount factor lower). Furthermore, note that $\bar{D}^{S C}-\bar{D}^{R C}=\delta c$. Hence, $d\left(\bar{D}^{S C}-\bar{D}^{R C}\right) / d \delta>0$, and a higher risk and consequently lower discount factor reduces the difference between maximum debt under formal spot and relational contracts.

To test this prediction, we interact the risk variable with the COEC variable. The results are provided in Table 6. As expected, the interaction term Risk $k_{s t} \times C O E C_{j t}$ is associated with a higher external-debt-to-capital ratio, while the average impact of $C O E C_{j t}$ and $R i s k_{s t}$ remains negative and statistically significant.

The relationship between a firm's bankruptcy risk and the discount factor in our model is probably nonlinear. In a low-risk environment, a slight increase in risk is arguably less likely to affect the probability of a bankruptcy than in a high-risk environment. To highlight this aspect, we define two indicator variables to distinguish high-risk from lower-risk observations. We define the binary variables Highrisk ${ }_{i t}^{75}$ and Highrisk $k_{i t}^{90}$ indicating whether an observation belongs to the $75 \%$ or the $90 \%$ percentile of the distribution of Risk $k_{s t}$. Correspondingly, low-risk observations are those where Highrisk $_{i t}^{75}=0$ or Highrisk $k_{i t}^{90}=0$. The last 4 columns of Table 6 show that observations where Highrisk $_{i t}^{75}=1$ and Highrisk $k_{i t}^{90}=1$, i.e. those firms that operate in a high-risk environment, respond less to changes in $C O E C_{j t}$.

- INCLUde TABle 6: RISK - 
We can show by way of graphical illustration how the predicted impact of $C O E C_{j t}$ changes along its observed values and how operating in a high-risk environment changes its marginal impact.

Panel (a) of Figure 2 depicts the predicted external debt ratio for variations in $C O E C_{j t}$, where the effect of all other explanatory variables is kept constant. It distinguishes between firms operating in a high-risk environment (the solid line) with Highrisk $k_{i t}^{90}=1$ and those operating in a low-risk environment (the dashed line) with Highrisk $k_{i t}^{90}=0$. Panel (b) depicts the marginal effect of one-unit increases in $C O E C_{j t}$.

Figure 2: Effect of COEC - High- vs. low risk

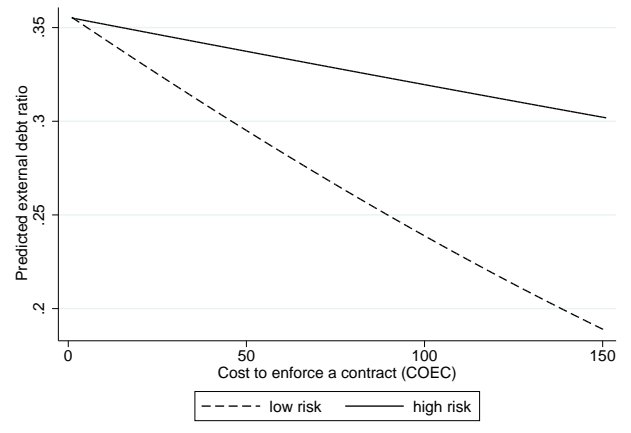

(a) Predicted external debt ratio

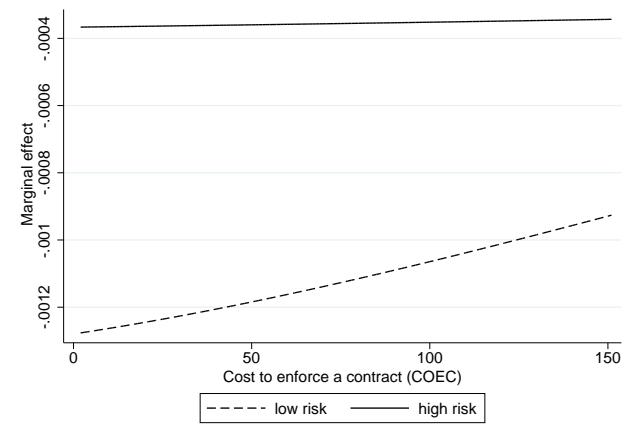

(b) Marginal effect of $C O E C_{j t}$

The figures suggest the following. First, the impact of $C O E C_{j t}$ in a high-risk environment is less pronounced, i.e. less negative. While the impact of $C O E C_{j t}$ in a normal or low-risk environment is quite substantial (compare the predicted external debt ratio for extreme values of the cost to enforce a contract), the external-debt response function becomes relatively (but not fully) flat. Second, the gradient, depicted in Panel (b), is negative for both high- and low-risk firms. Third, for higher values of $C O E C_{j t}$, the gradient becomes less negative, i.e. the marginal effect decreases in $C O E C_{j t}$. The latter can be seen from the positively sloped marginal effect curve.

\subsection{Quantification}

Our estimates suggest that the impact of $C O E C_{j t}$ is quite substantial, especially when we directly compare firms in countries with bad institutions to firms in countries with 
good institutions (low enforcement costs). For this reason, let us predict the external debt ratio and consider (large) discrete jumps in $C O E C_{j t}{ }^{25}$ We are interested in such estimates, as countries can influence the cost to enforce a contract quite significantly by implementing reforms (see Table A1). As reported before, a discrete jump in $C O E C_{j t}$ by one standard deviation (11.15) from its mean value of 22.53 to 33.68 suggests a decrease in the external debt ratio of 0.0127 (or 1.27 percentage points). Let us consider stepwise increases in $C O E C_{j t}$ by 10 percentage points, starting from a value of 0 , to a value of 150 . Figure 4 displays the absolute changes in the predicted external debt ratio along 10 percentage points jumps in $C O E C_{j t}$. What it confirms from above is that the effect becomes significantly smaller when values of $C O E C_{j t}$ become higher.

Figure 3: Discrete jumps in COEC

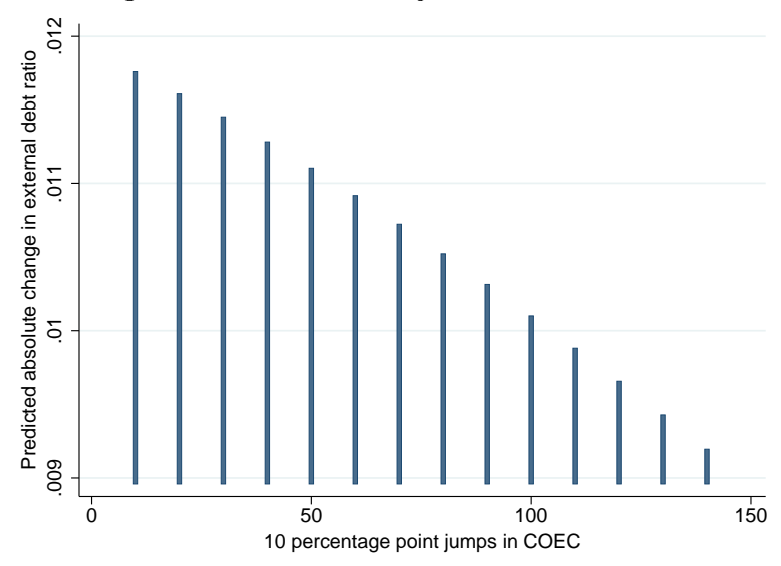

Another interesting quantification using our estimation results from above may involve comparisons of average firms in given countries, to learn how much of the difference in debt-to-capital ratios is explained by the institutional environment. In 2012, for example, the cost of enforcing contracts amounted to $18.4 \%$ and $22.3 \%$ of the claim in the U.S. and Canada, respectively. Our estimations imply that, under the higher Canadian contract enforcement cost, the average U.S. firm would have a 0.9 percentage points lower external-debt-to-capital ratio.

We can finally use the fractional response model and rank firms according to their responsiveness to changes in $C O E C_{j t}$. To do this, we calculate the difference in predicted external debt ratios when $C O E C_{j t}$ changes from its actual value to a value of

\footnotetext{
${ }^{25}$ All quantifications in this section are based on the basic results presented in Table 2.
} 
zero, i.e. there is no cost associated with enforcing a contract. The results indicate that the responsiveness of external debt financing is highest for those firms whose operations are related to "manufacture of chemicals and chemical products" or to "wholesale trade".

\subsection{Alternative Data Source}

We finally replicate the basic results from above using Orbis, a database provided by Bureau van Dijk. Orbis does not allow us to distinguish between internal and external debt - we only observe total debt - and it is not collected on the basis of mandatory reporting (which guarantees very reliable and high-quality information in MiDi). However, the advantage of this dataset is that it includes both domestic and multinational firms from all over the world.

The results, based on 4,278,119 observations and the same specification and approach as used above, are shown in Table 7 . The estimated coefficient on $C O E C_{j t}$ is negative and statistically significant. This confirms our results from above. Note that the estimates in Table 7 are not fully comparable to the ones from above as the dependent variable measures long-term debt as reported in Orbis.

\section{Conclusion}

This paper shows that institutions, and particularly the costs associated with enforcing formal contracts, matter for firms' financing decisions. We model the relationship of an upstream party supplying an intermediate good to a downstream party, where contracts are needed to ensure high quality of the good delivered. In its Doing Business database, the World Bank provides a measure on the costs of a hypothetical commercial dispute between upstream and downstream parties. Along the lines of this hypothetical case, for which the World Bank measures the costs of enforcing contracts, we propose a theoretical model where enforceable contracts can be used to guarantee high quality of the good supplied. Formal contracts are costly, however, and if the costs are too high, relational contracts - self-enforcing informal arrangements that can be sustained in long-term relationships - are needed. We show that these relational contracts can only be sustained if debt is not too high, suggesting a negative relationship between debt financing and costs associated with enforcing formal contracts. The reason for the negative implications of debt financing on relational contracts is that a firm's commitment in relational contracts is determined by its future profits in the cooperative 
relationship, and the need to repay debt reduces future profits.

We use two sources of data to explore the main predictions of our model empirically. First, data from the World Bank on the cost to enforce a contract for 124 countries. Second, balance-sheet data to calculate debt-to-capital ratios for 33,583 firms over 9 years. Unconditional correlations suggest a clear negative relation between the cost of contract enforcement and debt financing. Conditional estimates suggest that an increase in the 'cost to enforce a contract (in \% of claim)' by one standard deviation leads to a reduction in the average debt-to-capital ratio of about 1.3 percentage points. This is, compared to other variables relevant in the context of capital structure choice, quite a substantial effect. We argue that the effect of the cost-of-enforcing-a-contract variable is well identified by our estimation approach, which conditions on time-constant firm heterogeneity and focuses on changes in the measured cost over time, where the latter changes are usually related to institutional reforms. A number of robustness and plausibility checks, which test features and predictions of our theoretical model, conclusively shows that the cost of enforcing formal contracts governing non-financial relationships between firms affects a firm's financing structure. This finding demonstrates that legal institutions can have indirect and far reaching effects on firm's organizational choices.

\section{References}

[1] Abreu, D. (1988), "On the theory of infinitely repeated games with discounting," Econometrica, 56, 383-396.

[2] Acemoglu, D., S. Johnson and J.A. Robinson (2005), "Institutions as the fundamental cause of long-run growth," In: Aghion, P., S. Durlauf (Eds.), Handbook of Economic Growth, vol. 1A. North-Holland, London, 386-464.

[3] Baker, G., R. Gibbons, and K.J. Murphy (1994), "Subjective performance measures in optimal incentive contracts," Quarterly Journal of Economics, 109, 1125-1156.

[4] Baker, S., and A.H. Choi (2016), "Embedding costly litigation into repeat interactions," working paper.

[5] Bakos, Y., and C. Dellarocas (2011), "Cooperation without enforcement? A comparative analysis of litigation and online reputation as quality assurance mechanisms," Management Science, 57, 1944-1962. 
[6] Barron, D., and J. Li (2016), "Financing constraints and relational contracts," mimeo.

[7] Battigalli, P., and Giovanni Maggi (2008), "Costly contracting in a long-term relationship," RAND Journal of Economics, 39(2), 352-377.

[8] Berk, J. B., R. Stanton, and J. Zechner (2010), "Human capital, bankruptcy, and capital structure," The Journal of Finance, 65(3), 891-926.

[9] Besley, T. (2015), "Law, regulation, and the business climate: The nature and influence of the World Bank Doing Business project," Journal of Economic Perspectives, 29(3), 99-120.

[10] Buettner, T., M. Overesch, U. Schreiber, and G. Wamser (2009), "Taxation and capital structure choice-evidence from a panel of German multinationals," Economics Letters, 105(3), 309-311.

[11] Boehm, (2013), "The Impact of Contract Enforcement Costs on Outsourcing and Aggregate Productivity", unpublished manuscript.

[12] Chamberlain, G. (1980), "Panel data," Handbook of Econometrics, 2, 1247-1318.

[13] DeAngelo, H., and R.W. Masulis, (1980), "Optimal capital structure under corporate and personal taxation," Journal of Financial Economics, 8(1), 3-29.

[14] Desai, M.A., C.F. Foley, and J.R. Hines (2004), "A multinational perspective on capital structure choice and internal capital markets," The Journal of Finance, $59(6), 2451-2487$.

[15] Desai, M.A., C.F. Foley, and J.R. Hines (2008), "Capital structure with risky foreign investment," Journal of Financial Economics, 88(3), 534-553.

[16] Djankov, S., R. LaPorta, F. Lopez-De-Silanes, and A. Shleifer (2003), "Courts," Quarterly Journal of Economics, 118(2), 453-517.

[17] Djankov, S., C. McLiesh, and A. Shleifer (2007), "Private credit in 129 countries," Journal of Financial Economics, 84(2), 299-329.

[18] Fahn, M., V. Merlo, and G. Wamser (2017), "The Commitment Role of Equity Financing," RSIT working paper 01/2017. 
[19] Farnsworth, K. (2004), Corporate power and social policy in a global economy: British welfare under the influence, MIT Press.

[20] Frank, M.Z., and V.K. Goyal (2009), "Capital structure decisions: which factors are reliably important?" Financial Management, 38(1), 1-37.

[21] Ganuza, J.J., F. Gomez, and M. Robles (2016), "Product liability versus reputation," Journal of Law, Economics, and Organization, 32(2), 213-241.

[22] Gibbons, R., and R. Henderson (2013), "What do managers do? Exploring persistent performance differences among seemingly similar enterprises," in R. Gibbons and John Robert (Eds.), The Handbook of Organizational Economics, Princeton University Press, 680-731.

[23] Graham, J.R. (2000), "How big are the tax benefits of debt?" Journal of Finance, $55,1901-1941$.

[24] Graham, J.R., and C.R. Harvey (2001), "The theory and practice of corporate finance: Evidence from the field" Journal of Financial Economics, 60(2), 187-243.

[25] Graham, J.R., and M.T. Leary (2011), "A review of empirical capital structure research and directions for the future," Annual Review of Financial Economics, 3, 309-345.

[26] Harris, M., and A. Raviv (1991), "The theory of capital structure," Journal of Finance, 46, 297-355.

[27] Huizinga, H., L. Laeven, and G. Nicodeme (2008), "Capital structure and international debt shifting," Journal of Financial Economics, 88(1), 80-118.

[28] Kesternich, I., and M. Schnitzer (2010), "Who is afraid of political risk? Multinational firms and their choice of capital structure," Journal of International Economics, 82(2), 208-218.

[29] Kreps, D.M., and R. Wilson (1982), "Sequential equilibria," Econometrica, 50(4), 863-894.

[30] La Porta, R., F. Lopez-de-Silanes, and A. Shleifer (2008), "The economic consequences of legal origins," Journal of Economic Literature 46(2), 285-332. 
[31] Lipponer, A. (2009), Microdatabase Direct Investment-MiDi. A Brief Guide, Deutsche Bundesbank Technical Documentation, Frankfurt.

[32] MacKie-Mason, J.K. (1990), "Do taxes affect corporate financing decisions?" The Journal of Finance, 45(5), 1471-1493.

[33] Maksimovic, V., and S. Titman (1991), "Financial policy and reputation for product quality," Review of Financial Studies, 4, 175-200.

[34] Malcomson, J. (2013), "Relational incentive contracts," in R. Gibbons and John Robert (edts.), The Handbook of Organizational Economics, Princeton University Press, 1014-1065.

[35] Martimort, D., A. Semenov, and L. Stole (2016), "A theory of contracts with limited enforcement," Review of Economic Studies, forthcoming.

[36] Myers, S.C. (1977), "Determinants of corporate borrowing," Journal of Financial Economics, 5, 147-175.

[37] Myers, S.C. (2001), "Capital structure," The Journal of Economic Perspectives, 15(2), 81-102.

[38] Nunn, N. (2007), "Relationship-Specificity, Incomplete Contracts, and the Pattern of Trade," Quarterly Journal of Economics, 122(2), 569-600.

[39] Nunn, N., and D. Trefler (2014), "Domestic institutions as a source of comparative advantage," Handbook of International Economics, 4, 263-315.

[40] Papke, L.E., and J.M. Wooldridge (2008), "Panel data methods for fractional response variables with an application to test pass rates," Journal of Econometrics, 145(1), 121-133.

[41] Posner, R.A. (2007), Economic analysis of law, Aspen.

[42] Rajan, R.G., and L. Zingales (1995), "What do we know about capital structure? Some evidence from international data," The Journal of Finance, 50(5), 1421-1460.

[43] Shleifer, A., and D. Wolfenzon (2002), "Investor protection and equity markets", Journal of Financial Economics, 66(1), 3-27. 
[44] Strebulaev, I.A., and B. Yang (2013), "The mystery of zero-leverage firms," Journal of Financial Economics, 109(1), 1-23.

[45] Titman, S. (1984), "The effect of capital structure on a firm's liquidation decision," Journal of Financial Economics, 13, 137-151.

\section{Tables and Appendices}




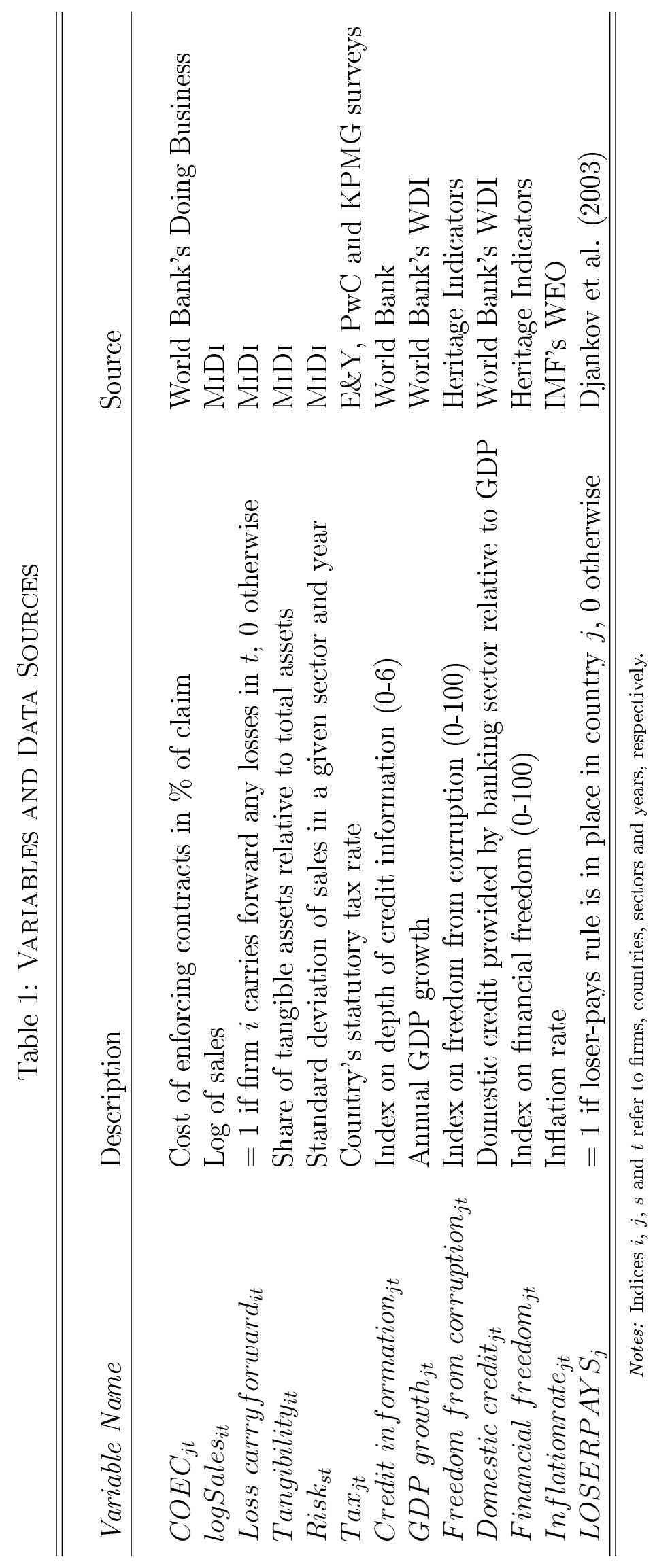


Table 2: Descriptive Statistics

\begin{tabular}{|c|c|c|}
\hline & Mean & (Std. Dev.) \\
\hline Share of external debt $\left(d_{i t}\right)$ & 0.329 & $(0.256)$ \\
\hline$C O E C_{j t}$ & 22.528 & $(11.154)$ \\
\hline $\log$ Sales $_{i t}$ & 2.995 & $(1.431)$ \\
\hline Loss carry forward $_{i t}$ & 0.293 & $(0.455)$ \\
\hline Tangibility $_{i t}$ & 0.270 & $(0.262)$ \\
\hline$R i s k_{s t}$ & 0.327 & $(0.347)$ \\
\hline $\operatorname{Tax}_{j t}$ & 0.285 & $(0.074)$ \\
\hline${\text { Credit in } \text { formation }_{j t}}$ & 4.846 & $(1.147)$ \\
\hline$G D P$ growth $_{j t}$ & 2.640 & $(3.622)$ \\
\hline${\text { Freedom } \text { from }_{\text {corruption }} \text { t }}$ & 62.634 & $(21.083)$ \\
\hline Domestic credit $_{j t}$ & 137.870 & $(65.407)$ \\
\hline 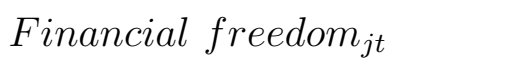 & 66.628 & $(17.706)$ \\
\hline${\text { Inflation } \text { rate }_{j}}$ & 3.133 & $(2.742)$ \\
\hline$L O S E R P A Y S_{j}^{(1)}$ & 0.375 & $(0.484)$ \\
\hline
\end{tabular}

Notes: Statistics based on 167,503 (1) 165,079) observations. A more detailed description of variables and data sources is provided in the text. 
Table 3: Estimation REsults

\begin{tabular}{|c|c|c|}
\hline & Coeff. & $\mathrm{APE}$ \\
\hline$C O E C_{j t}$ & $\begin{array}{c}-0.003^{* *} \\
(0.001)\end{array}$ & $\begin{array}{c}-0.001^{* *} \\
(0.0004)\end{array}$ \\
\hline $\log$ Sales $_{i t}$ & $\begin{array}{c}0.080^{* * *} \\
(0.004)\end{array}$ & $\begin{array}{c}0.029^{* * *} \\
(0.001)\end{array}$ \\
\hline Loss Carryforward $_{i t}$ & $\begin{array}{c}0.010^{* *} \\
(0.005)\end{array}$ & $\begin{array}{c}0.004^{* *} \\
(0.002)\end{array}$ \\
\hline Tangibility $_{i t}$ & $\begin{array}{c}0.015 \\
(0.020)\end{array}$ & $\begin{array}{c}0.005 \\
(0.007)\end{array}$ \\
\hline Risk $_{s t}$ & $\begin{array}{c}-0.023^{* * *} \\
(0.009)\end{array}$ & $\begin{array}{c}-0.008^{* * *} \\
(0.003)\end{array}$ \\
\hline $\operatorname{Tax}_{j t}$ & $\begin{array}{c}0.184^{* *} \\
(0.093)\end{array}$ & $\begin{array}{c}0.066^{* *} \\
(0.033)\end{array}$ \\
\hline${\text { Credit in } \text { formation }_{j t}}$ & $\begin{array}{c}-0.009^{* *} \\
(0.004)\end{array}$ & $\begin{array}{c}-0.003^{* *} \\
(0.001)\end{array}$ \\
\hline$G D P$ growth $_{j t}$ & $\begin{array}{l}0.002^{*} \\
(0.001)\end{array}$ & $\begin{array}{c}0.001^{*} \\
(0.0003)\end{array}$ \\
\hline Freedom $_{\text {from }}$ corruption $_{j t}$ & $\begin{array}{c}0.001 \\
(0.001)\end{array}$ & $\begin{array}{c}0.0002 \\
(0.0002)\end{array}$ \\
\hline Domestic credit $_{j t}$ & $\begin{array}{c}-0.001^{* * *} \\
(0.0002)\end{array}$ & $\begin{array}{c}-0.0002^{* * *} \\
(0.0001)\end{array}$ \\
\hline Financial freedom $_{j t}$ & $\begin{array}{c}-0.00004 \\
(0.0003)\end{array}$ & $\begin{array}{l}-0.00001 \\
(0.0001)\end{array}$ \\
\hline Inflation rate $_{j t}$ & $\begin{array}{c}0.001 \\
(0.001)\end{array}$ & $\begin{array}{c}0.0004 \\
(0.0003)\end{array}$ \\
\hline
\end{tabular}

Notes: 167,503 observations. Fractional response model estimated by Pooled QMLE. The dependent variable refers to the external-debt-to-capital ratio $d_{i t}$. All regressions include time dummies and firm-specific fixed effects (modeled as described in Section 4.1). Robust standard errors reported in parentheses are based on panel bootstrapping. ${ }^{*}, * *$, and *** indicate significance at $10 \%, 5 \%$, and $1 \%$, respectively. 
Table 4: Measurement Issues

\begin{tabular}{|c|c|c|c|c|}
\hline & Coeff. & APE & Coeff. & $\mathrm{APE}$ \\
\hline$C O E C_{j t}$ & $\begin{array}{c}-0.004^{* * *} \\
(0.001)\end{array}$ & $\begin{array}{c}-0.001^{* * *} \\
(0.001)\end{array}$ & & \\
\hline $\log C O E C_{j t}$ & & & $\begin{array}{c}-0.099^{* * *} \\
(0.028)\end{array}$ & $\begin{array}{c}-0.036^{* * *} \\
(0.010)\end{array}$ \\
\hline $\log$ Sales $_{i t}$ & $\begin{array}{c}0.079^{* * *} \\
(0.004)\end{array}$ & $\begin{array}{c}0.028^{* * *} \\
(0.001)\end{array}$ & $\begin{array}{c}0.080^{* * *} \\
(0.004)\end{array}$ & $\begin{array}{c}0.029^{* * *} \\
(0.001)\end{array}$ \\
\hline Loss Carry forward $_{i t}$ & $\begin{array}{c}0.010^{* *} \\
(0.005)\end{array}$ & $\begin{array}{c}0.004^{* *} \\
(0.002)\end{array}$ & $\begin{array}{c}0.010^{* *} \\
(0.005)\end{array}$ & $\begin{array}{c}0.004^{* *} \\
(0.001)\end{array}$ \\
\hline Tangibility $_{i t}$ & $\begin{array}{c}0.016 \\
(0.020)\end{array}$ & $\begin{array}{c}0.006 \\
(0.007)\end{array}$ & $\begin{array}{c}0.015 \\
(0.020)\end{array}$ & $\begin{array}{c}0.005 \\
(0.007)\end{array}$ \\
\hline Risk $_{s t}$ & $\begin{array}{c}-0.023^{* *} \\
(0.009)\end{array}$ & $\begin{array}{c}-0.008^{* *} \\
(0.003)\end{array}$ & $\begin{array}{c}-0.023^{* * *} \\
(0.009)\end{array}$ & $\begin{array}{c}-0.008^{* * *} \\
(0.003)\end{array}$ \\
\hline $\operatorname{Tax}_{j t}$ & $\begin{array}{c}0.289^{* * *} \\
(0.096)\end{array}$ & $\begin{array}{c}0.104^{* * *} \\
(0.035)\end{array}$ & $\begin{array}{l}0.171^{*} \\
(0.092)\end{array}$ & $\begin{array}{l}0.061^{*} \\
(0.033)\end{array}$ \\
\hline${\text { Credit in } \text { formation }_{j t}}$ & $\begin{array}{c}-0.008^{* *} \\
(0.003)\end{array}$ & $\begin{array}{c}-0.003^{* *} \\
(0.001)\end{array}$ & $\begin{array}{c}-0.009^{* * *} \\
(0.003)\end{array}$ & $\begin{array}{c}-0.003^{* * *} \\
(0.001)\end{array}$ \\
\hline$G D P$ growth $_{j t}$ & $\begin{array}{c}0.003^{* * *} \\
(0.001)\end{array}$ & $\begin{array}{c}0.0011^{* * *} \\
(0.0003)\end{array}$ & $\begin{array}{l}0.002^{*} \\
(0.001)\end{array}$ & $\begin{array}{c}0.001^{*} \\
(0.0003)\end{array}$ \\
\hline Freedom $_{\text {from corruption }}$ ct & $\begin{array}{l}0.001^{*} \\
(0.001)\end{array}$ & $\begin{array}{l}0.0003^{*} \\
(0.0002)\end{array}$ & $\begin{array}{c}0.0005 \\
(0.0005)\end{array}$ & $\begin{array}{c}0.0002 \\
(0.0002)\end{array}$ \\
\hline${\text { Domestic } \text { credit }_{j t}}$ & & & $\begin{array}{c}-0.0006^{* * *} \\
(0.0002)\end{array}$ & $\begin{array}{c}-0.0002^{* * *} \\
(0.0001)\end{array}$ \\
\hline 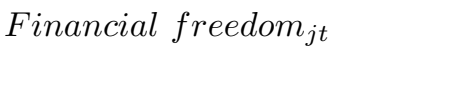 & & & $\begin{array}{l}-0.0001 \\
(0.0002)\end{array}$ & $\begin{array}{c}-0.00004 \\
(0.00009)\end{array}$ \\
\hline Inflation rate $_{j t}$ & & & $\begin{array}{c}0.0010 \\
(0.0009)\end{array}$ & $\begin{array}{c}0.0004 \\
(0.0003)\end{array}$ \\
\hline
\end{tabular}

Notes: 167,503 observations. Fractional response model estimated by Pooled QMLE. The dependent variable refers to the external-debt-to-capital ratio $d_{i t}$. All regressions include time dummies and firm-specific fixed effects (modeled as described in Section 4.1). Robust standard errors reported in parentheses are based on panel bootstrapping. ${ }^{*},{ }^{* *}$, and *** indicate significance at $10 \%, 5 \%$, and $1 \%$, respectively. 
Table 5: Loser Pays Rule

\begin{tabular}{|c|c|c|c|c|}
\hline & Coeff. & $\mathrm{APE}$ & Coeff. & $\mathrm{APE}$ \\
\hline$C O E C_{j t}$ & $\begin{array}{c}-0.004^{* * *} \\
(0.001)\end{array}$ & $\begin{array}{c}-0.001^{* * *} \\
0.001\end{array}$ & $\begin{array}{c}-0.005^{*} \\
(0.003)\end{array}$ & $\begin{array}{c}-0.002^{*} \\
(0.001)\end{array}$ \\
\hline$L O S E R P A Y S_{j} \times C O E C_{j t}$ & $\begin{array}{c}0.001^{*} \\
(0.0003)\end{array}$ & $\begin{array}{l}0.0002^{*} \\
(0.0001)\end{array}$ & & \\
\hline $\log$ Sales $_{i t}$ & $\begin{array}{c}0.080^{* * *} \\
(0.004)\end{array}$ & $\begin{array}{c}0.029^{* * *} \\
(0.001)\end{array}$ & $\begin{array}{c}0.080^{* * *} \\
(0.005)\end{array}$ & $\begin{array}{c}0.029^{* * *} \\
(0.002)\end{array}$ \\
\hline Loss Carry forward $_{i t}$ & $\begin{array}{l}0.010^{*} \\
(0.005)\end{array}$ & $\begin{array}{l}0.004^{*} \\
(0.002)\end{array}$ & $\begin{array}{c}0.015^{* *} \\
(0.007)\end{array}$ & $\begin{array}{c}0.005^{* *} \\
(0.002)\end{array}$ \\
\hline Tangibility $_{i t}$ & $\begin{array}{c}0.016 \\
(0.020)\end{array}$ & $\begin{array}{c}0.006 \\
(0.007)\end{array}$ & $\begin{array}{l}0.041^{*} \\
(0.025)\end{array}$ & $\begin{array}{l}0.015^{*} \\
(0.009)\end{array}$ \\
\hline Risk $_{s t}$ & $\begin{array}{c}-0.023^{* * *} \\
(0.009)\end{array}$ & $\begin{array}{c}-0.008^{* * *} \\
(0.003)\end{array}$ & $\begin{array}{c}-0.037^{* * *} \\
(0.012)\end{array}$ & $\begin{array}{c}-0.013^{* * *} \\
(0.004)\end{array}$ \\
\hline $\operatorname{Tax}_{j t}$ & $\begin{array}{c}0.153^{*} \\
(0.083)\end{array}$ & $\begin{array}{l}0.055^{*} \\
(0.030)\end{array}$ & $\begin{array}{c}0.084 \\
(0.116)\end{array}$ & $\begin{array}{c}0.030 \\
(0.041)\end{array}$ \\
\hline${\text { Credit in } \text { formation }_{j t}}$ & $\begin{array}{c}-0.009^{*} \\
(0.004)\end{array}$ & $\begin{array}{c}-0.003^{*} \\
(0.001)\end{array}$ & $\begin{array}{c}-0.016^{* * *} \\
(0.005)\end{array}$ & $\begin{array}{c}-0.006^{* * *} \\
(0.002)\end{array}$ \\
\hline$G D P$ growth $_{j t}$ & $\begin{array}{c}0.002^{* *} \\
(0.001)\end{array}$ & $\begin{array}{l}0.001^{* *} \\
(0.0003)\end{array}$ & $\begin{array}{c}0.003^{* * *} \\
(0.001)\end{array}$ & $\begin{array}{c}0.001^{* * *} \\
(0.0004)\end{array}$ \\
\hline Freedom $_{\text {from corruption }}$ jt & $\begin{array}{c}0.001 \\
(0.001)\end{array}$ & $\begin{array}{c}0.0002 \\
(0.0002)\end{array}$ & $\begin{array}{c}0.0012^{*} \\
(0.001)\end{array}$ & $\begin{array}{l}0.0004^{*} \\
(0.0002)\end{array}$ \\
\hline 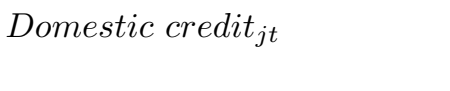 & $\begin{array}{c}-0.001^{* * *} \\
(0.0002)\end{array}$ & $\begin{array}{c}-0.0002^{* * *} \\
(0.0001)\end{array}$ & $\begin{array}{c}-0.001^{* * *} \\
(0.0002)\end{array}$ & $\begin{array}{c}-0.0003^{* * *} \\
(0.0001)\end{array}$ \\
\hline${\text { Financial } \text { freedom }_{j t}}$ & $\begin{array}{l}-0.0001 \\
(0.0003)\end{array}$ & $\begin{array}{l}-0.00004 \\
(0.0001)\end{array}$ & $\begin{array}{c}0.001^{*} \\
(0.0003)\end{array}$ & $\begin{array}{l}0.0002^{*} \\
(0.0001)\end{array}$ \\
\hline Inflation $_{\text {rate }}{ }_{j t}$ & $\begin{array}{l}0.002^{*} \\
(0.001)\end{array}$ & $\begin{array}{c}0.001^{*} \\
(0.0003)\end{array}$ & $\begin{array}{c}0.002 * * \\
(0.001)\end{array}$ & $\begin{array}{l}0.001^{* *} \\
(0.0004)\end{array}$ \\
\hline
\end{tabular}

Notes: 165,079 observations. Fractional response model estimated by Pooled QMLE. The dependent variable refers to the external-debt-to-capital ratio $d_{i t}$. All regressions include time dummies and firm-specific fixed effects (modeled as described in Section 4.1). Robust standard errors reported in parentheses are based on panel bootstrapping. *, **, and $* * *$ indicate significance at $10 \%, 5 \%$, and $1 \%$, respectively. 


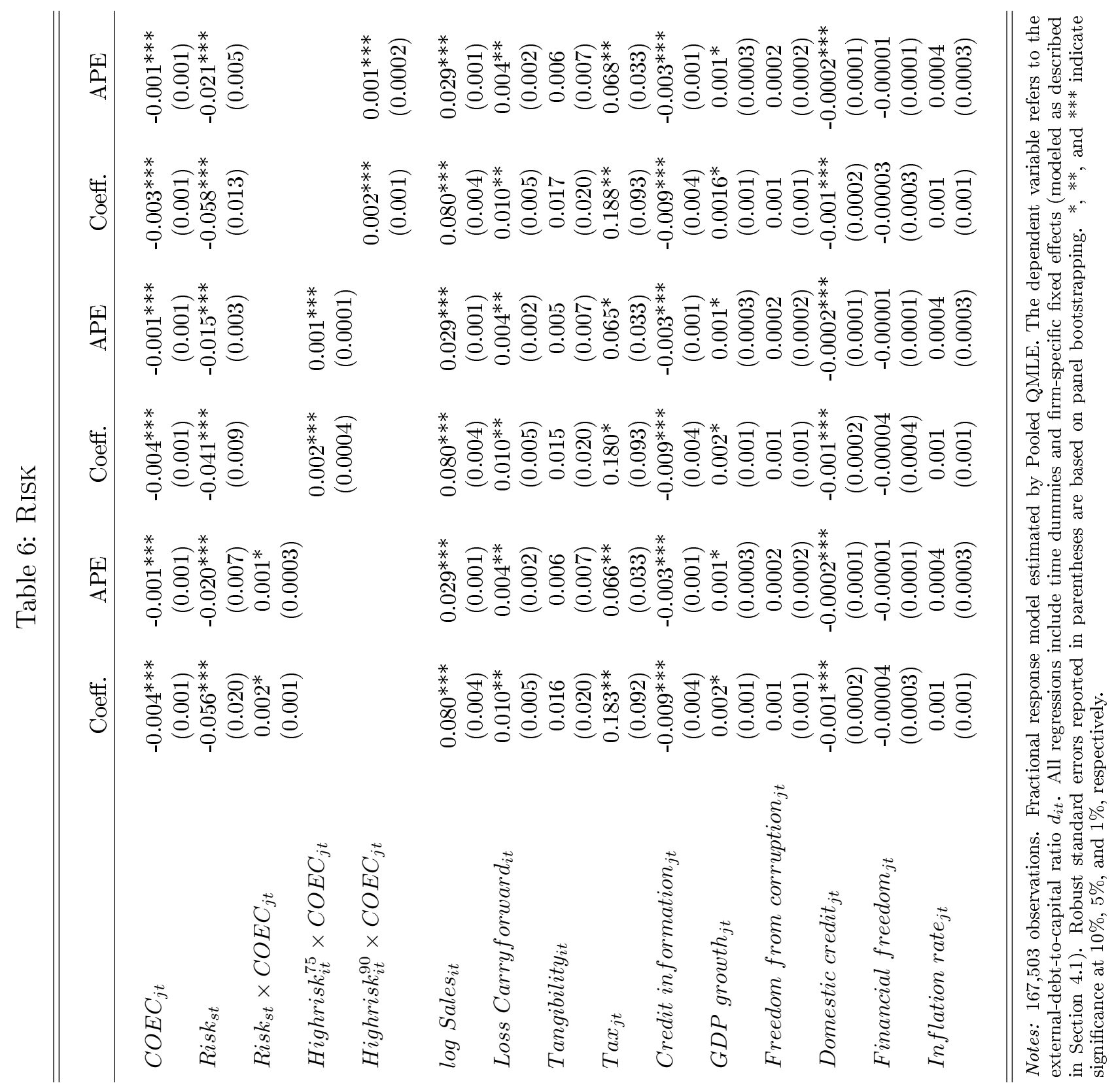


Table 7: Alternative Data

\begin{tabular}{|c|c|c|}
\hline & Coeff. & APE \\
\hline$C O E C_{j t}$ & $\begin{array}{c}-0.005^{* * *} \\
(0.001)\end{array}$ & $\begin{array}{c}-0.001^{* * *} \\
(0.0002)\end{array}$ \\
\hline $\log$ Sales $_{i t}$ & $\begin{array}{c}-0.006^{* * *} \\
(0.001)\end{array}$ & $\begin{array}{c}-0.001^{* * *} \\
(0.0002)\end{array}$ \\
\hline Loss Carryforward $_{i t}$ & $\begin{array}{c}0.073^{* * *} \\
(0.001)\end{array}$ & $\begin{array}{c}0.014^{* * *} \\
(0.0002)\end{array}$ \\
\hline Tangibility $y_{i t}$ & $\begin{array}{c}0.642^{* * *} \\
(0.006)\end{array}$ & $\begin{array}{c}0.122^{* * *} \\
(0.001)\end{array}$ \\
\hline$R i s k_{s t}$ & $\begin{array}{c}-0.000 * * * \\
(0.000)\end{array}$ & $\begin{array}{c}-0.000 * * * \\
(0.000)\end{array}$ \\
\hline $\operatorname{Tax}_{j t}$ & $\begin{array}{c}1.740^{* * *} \\
(0.027)\end{array}$ & $\begin{array}{c}0.330^{* * *} \\
(0.005)\end{array}$ \\
\hline 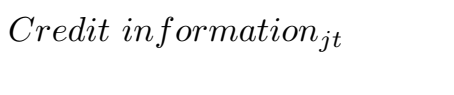 & $\begin{array}{c}-0.006^{* * *} \\
(0.001)\end{array}$ & $\begin{array}{c}-0.001^{* * *} \\
(0.0003)\end{array}$ \\
\hline$G D P$ growth $_{j t}$ & $\begin{array}{c}0.001^{* * *} \\
(0.0003)\end{array}$ & $\begin{array}{c}0.0002^{* * *} \\
(0.0001)\end{array}$ \\
\hline Freedom from corruption $_{j t}$ & $\begin{array}{c}-0.005^{* * *} \\
(0.0002)\end{array}$ & $\begin{array}{l}-0.001^{* * *} \\
(0.00003)\end{array}$ \\
\hline Domestic $_{\text {credit }}{ }_{j t}$ & $\begin{array}{c}0.001^{* * *} \\
(0.000)\end{array}$ & $\begin{array}{c}0.0001^{* * *} \\
(0.000)\end{array}$ \\
\hline 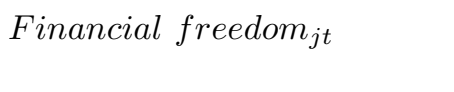 & $\begin{array}{c}-0.004^{* * *} \\
(0.0001)\end{array}$ & $\begin{array}{l}-0.001^{* * *} \\
(0.00002)\end{array}$ \\
\hline Inflation rate $_{j t}$ & $\begin{array}{l}0.004^{* * *} \\
(0.0004)\end{array}$ & $\begin{array}{l}0.001^{* * *} \\
(0.0001)\end{array}$ \\
\hline
\end{tabular}

Notes: 4,278,119 observations from Orbis. Fractional response model estimated by Pooled QMLE. The dependent variable refers to the debt-to-capital ratio. All regressions include time dummies and firm-specific fixed effects (modeled as described in Section 4.1). Robust standard errors reported in parentheses are based on panel bootstrapping. *, **, and $* * *$ indicate significance at $10 \%, 5 \%$, and $1 \%$, respectively. 


\section{Appendix I - Omitted Proofs}

Proof of Proposition 1. The threshold $\bar{D}^{S C}=\delta^{2} \frac{\theta-c}{1-\delta}$ immediately follows from plugging in $r=(1-\delta) / \delta$ and $\Pi=(\theta-c) /(1-\delta)-D / \delta$ into the downstream party's no-default condition, $-r D+\delta \Pi \geq 0$. In case formal spot contracts can be used, i.e. for $K \leq \theta$, no further constraints must be considered.

In case relational contracts are used, the (DE) constraint $-P-r D+\delta \Pi \geq 0$ is tighter than the (ND) constraint and thus determines the maximum debt threshold in this case. Plugging $P=c, r=(1-\delta) / \delta$ and $\Pi=(\theta-c) /(1-\delta)-D / \delta$ into the (DE) constraint gives $\bar{D}^{R C}=\delta^{2} \frac{\left(\theta-\frac{c}{\delta}\right)}{1-\delta}$.

For the case of formal enforcement in long-term arrangements, we construct a profitmaximizing equilibrium (i.e., with $w+P=c$ ) where, although $K>\theta$, the upstream party sues the downstream party given the latter refused to pay $P$ even though quality has been high. In the following, we denote the costs the downstream party has to bear after a verdict against her by $\tilde{K}$. Furthermore, the upstream party's off-path continuation profits are denoted by $\tilde{U}=(\tilde{w}+\tilde{P}-c) /(1-\delta)$, and the downstream party's off-path continuation profits by $\tilde{\Pi}=(\theta-\tilde{w}-\tilde{P}-r \tilde{D}) /(1-\delta)$.

Let us now derive the constraint that must hold in order for this to be an equilibrium. Starting with the upstream party, its on-path individual rationality and incentive compatibility constraints must hold (as specified above) and will bind in a profit-maximizing equilibrium. Furthermore, as pointed out above, it must be optimal for the upstream party to sue the downstream party in case the latter refused to pay $P$ :

$$
\theta-K+\delta \tilde{U} \geq 0
$$

In addition, it must remain optimal for the upstream party to accept the contract and provide high quality off the equilibrium path. For $\theta-K<0$, constraint (4) implies $\tilde{U}>0$, hence the upstream party accepts the off-path contract. Its off-path (IC) constraint equals $\tilde{P}-c+\delta \tilde{U} \geq 0$. There, we can set $\tilde{P}=c$ without loss of generality, so that the rent the upstream party is awarded to after a deviation by the downstream party is solely provided via the fixed payment $\tilde{w}$, and the off-path (IC) constraint holds.

For the downstream party it must not be optimal to default. On the equilibrium path, this is given by (ND). Off the equilibrium path and immediately after the devia- 
tion, this condition becomes

$$
-(1+r) D+\tilde{D}-\tilde{K}+\delta \tilde{\Pi} \geq-\tilde{K}
$$

There, note that we assume that the downstream party cannot get around paying $\tilde{K}$ by a default, hence it enters both sides of the constraint.

At later instance after the deviations, this constraint equals

$$
-r \tilde{D}+\delta \tilde{\Pi} \geq 0
$$

Note that it is weakly optimal to set $\tilde{D}=D$, for the following reason: Taking into account that $r=(1-\delta) / \delta$, condition (5) becomes $-\frac{D}{\delta}+\delta \frac{(\theta-\tilde{w}-\tilde{P})}{(1-\delta)} \geq 0$, and is therefore independent of $\tilde{D}$. Furthermore, condition (4) becomes $-\frac{\tilde{D}}{\delta}+\delta \frac{(\theta-\tilde{w}-\tilde{P})}{(1-\delta)} \geq 0$. If the downstream party wants to keep debt as high as feasible (for reasons outside our model), she will set on-path debt $D$ to the level where condition $(5)$ binds, i.e. $-\frac{D}{\delta}+\delta \frac{(\theta-\tilde{w}-\tilde{P})}{(1-\delta)}=$ 0 . Then, because $-\frac{\tilde{D}}{\delta}+\delta \frac{(\theta-\tilde{w}-\tilde{P})}{(1-\delta)} \geq 0$, the maximum level of $\tilde{D}$ is the same as of $D$. If the downstream party does not want to keep debt as high as feasible, it is without loss of generality to set $\tilde{D}=D$. This implies that conditions (6) and (5) are equivalent, hence condition (6) can be omitted.

Furthermore, the (DE) constraint now equals $-P-r D+\delta \Pi \geq-P-(1+r) D+$ $\tilde{D}-\tilde{K}+\delta \tilde{\Pi}$, which (using $r=(1-\delta) / \delta$ ) becomes $\delta \frac{\theta-P-w}{1-\delta} \geq-\tilde{K}+\delta \frac{\theta-\tilde{w}-\tilde{P}}{1-\delta}$. This is automatically satisfied since $\tilde{w}+\tilde{P} \geq w+P$ and $\tilde{K} \geq 0$.

Payment of $P$ also is optimal off the equilibrium path, since the upstream party continues to sue the downstream party in case the latter refuses to pay ((4) still holds). Hence the off-path (DE) constraint equals $-\tilde{P}-r \tilde{D}+\delta \tilde{\Pi} \geq-\tilde{P}-r \tilde{D}+\delta \tilde{\Pi}-\tilde{K}$.

Off the equilibrium path it must remain optimal for the downstream party to offer $\tilde{w}$ and $\tilde{P}$ in every period. This can be supported by the following strategies:

When making an offer $\tilde{w}^{\prime}+\tilde{P}^{\prime}<\tilde{w}+\tilde{P}$ in one period, the upstream party expects the downstream party to also do so in all subsequent periods. Therefore, the upstream party does not deliver high quality because given it expects the downstream party to make offers below $\tilde{w}+\tilde{P}$, it will not sue the downstream party in case the latter refused to pay $\tilde{P}$. Therefore, the downstream party would not pay $\tilde{P}$ if high quality had been provided.

Hence, it is better for the downstream party to offer $\tilde{w}+\tilde{P}$ compared to a lower value (naturally, the downstream party would also prefer $\tilde{w}+\tilde{P}$ over a higher value). 
Concluding, the constraints (5) and (6), $\theta-K+\delta \tilde{U} \geq 0$ and $-r D+\delta \tilde{\Pi} \geq 0$, pin down whether an equilibrium can be constructed where the upstream party sues the downstream party even though $K>\theta$. It is weakly optimal to set $\tilde{w}$ and $\tilde{P}$ as small as possible, i.e. such that condition (5) binds. Then, $\theta-K+\delta \tilde{U}=0$ and $\tilde{w}+\tilde{P}=\frac{1-\delta}{\delta}(K-\theta)+c$. Plugging this into (5) gives

$$
D \leq \bar{D}^{L C}=\delta^{2} \frac{\theta-c}{1-\delta}-\delta(K-\theta) .
$$

Finally, comparing $\bar{D}^{R C}$ to $\bar{D}^{L C}$ gives that $\bar{D}^{R C}<\bar{D}^{L C}$ if and only if $K<c-\theta$. 


\section{Appendix II - Theoretical Extensions}

\section{Profit Tax}

In the main section, we assume that the direct costs of debt and equity financing are identical. Given interest rates are tax-deductible, though, debt is often regarded as effectively being cheaper than equity. Extending our model in this direction, we find that the downstream party should use as much debt as possible to maximize tax shields. But still, debt must not exceed a threshold above which a default becomes optimal. Compared to the analysis above, this threshold will not be affected by the tax level, thus the firm's uniquely optimal financing strategy involves a debt level that is exactly at the respective threshold (provided it is smaller than $I$ ).

Assume profits are taxed with the rate $\tau$ and that interest payments (as well as enforcement costs) can be deducted from taxable income. Furthermore, the interest paid to creditors still is $r=\frac{1-\delta}{\delta}$ (we hence abstract from potential taxes creditors have to pay on income from interest payments). Besides taxes, the environment is as before. Therefore, the downstream party's profits on the equilibrium path are $\Pi=\frac{(\theta-c-r D)(1-\tau)}{1-\delta}$ and $\Pi_{0}=-(I-D)+\delta \Pi=-I+\tau D+\delta \frac{(\theta-c)(1-\tau)}{1-\delta}$. Since $\partial \Pi_{0} / \partial D>0$, ceteris paribus the downstream party should borrow as much as possible. Taking into account the constraints that must hold to guarantee the provision of a high-quality intermediate good in every period, we get

Proposition 2 : Assume firms face a profit tax $\tau$. Then, the downstream party's uniquely optimal debt level $\hat{D}$ equals

- $\hat{D}^{S C}=\min \left\{I, \delta^{2} \frac{\theta-c}{1-\delta}\right\}$ for $K \leq \theta$

- $\hat{D}^{L C}=\min \left\{I, \delta^{2} \frac{\theta-c}{1-\delta}-\delta(K-\theta)\right\}$ for $\theta<K \leq \theta+c$

- $\hat{D}^{R C}=\min \left\{I, \delta^{2} \frac{\left(\theta-\frac{c}{\delta}\right)}{1-\delta}\right\}$ for $K>\theta+c$,

with $\hat{D}^{R C} \leq \hat{D}^{L C} \leq \hat{D}^{S C}$.

Proof of Proposition 2. Making use of the results we derived above (in case no profit tax iss present), the downstream party's objective is to maximize $\Pi_{0}=-(I-D)+\delta \Pi=$ $-I+\tau D+\delta \frac{(\theta-c)(1-\tau)}{1-\delta}$, subject to the relevant constraints. 
We first show that those constraints are independent of $\tau$ :

In case formal spot contracts are used, debt is restricted by the no-default (ND) constraint. This becomes

$$
(\theta-c-r D)(1-\tau)+\delta \frac{(\theta-c-r D)(1-\tau)}{1-\delta} \geq(\theta-c)(1-\tau),
$$

since taxes must also be paid off the equilibrium path. Hence, $(1-\tau)$ cancels out and the (ND) constraint is independent of $\tau$.

In case relational contracts are used, debt is restricted by the dynamic enforcement (DE) constraint. This becomes

$$
(\theta-c-r D)(1-\tau)+\delta \frac{(\theta-c-r D)(1-\tau)}{1-\delta} \geq \theta(1-\tau)
$$

hence $(1-\tau)$ cancels out as well.

Finally, concerning formal enforcement in long-term arrangenement, we showed in the proof to Proposition 1 that maximum debt is determined by the off-path rent the upstream party must be granted in order to sue the downstream party after the latter refused to pay $P$. This constraint equals $(w-c+P-K)(1-\tau)+\delta \frac{(\tilde{w}+\tilde{P}-c)(1-\tau)}{1-\delta} \geq 0$, where we implicitly assume that losses and the resulting tax shields can be carried forward (since $w-c+P=0$, the effective enforcement costs are reduced by the factor $\tau$ ). Taking into account that this constraint optimally binds, i.e., $\tilde{w}+\tilde{P}=\frac{1-\delta}{\delta}(K-\theta)+c$, the downstream party's off-path profits are $\tilde{\Pi}=\frac{(\theta-\tilde{w}-\tilde{P}-r D)(1-\tau)}{(1-\delta)}$. Plugging this into the downstream party's off-path no default constraint,

$$
(\theta-c-r D-\tilde{K})(1-\tau)+\delta \frac{(\theta-\tilde{w}-\tilde{P}-r D)(1-\tau)}{(1-\delta)} \geq(\theta-c-\tilde{K})(1-\tau),
$$

gives $D \leq \delta^{2} \frac{(\theta-c)}{(1-\delta)}+\delta(\theta-K)$, which is equivalent to above.

Since $\Pi_{0}$ is increasing in $D$, debt should be as high as feasible. The remainder, in particular the aspect which debt level is relevant for which size of enforcement costs $K$, follows from the proof to Proposition 1.

If firms face a proportional profit tax, the downstream party's optimal debt level is as high as possible. Interestingly, though, (DE) and no-default constraints (which pin down maximum feasible debt), are unaffected by the profit tax because those are deducted from on- and off-path profits and hence cancel out. Therefore, optimal debt 
levels with a tax are just the same as maximum debt levels without a tax.

\section{Investment by Upstream Party}

In this section, we show that our results go through if also the upstream party has to make a physical investment at the beginning of the game. Then, the downstream party's maximum debt threshold when using a relational contract still is strictly smaller than when using a formal contract. Concerning the upstream party, the resulting maximum debt threshold is weakly smaller when using a relational than when using a formal contract. Note that having the upstream party make an ex-ante investment implies that the downstream party cannot extract the whole rent because the upstream party would never make a costly investment if it was not sufficiently covered by future payoffs. Therefore, we also show in this section that our results do not rely on the downstream party keeping the whole rent generated in its relationship with the upstream party.

In the following, we assume that the also the upstream party has to make an exante investment, denoted $I_{u p}$ (the downstream's investment still is denoted $I$ ), and that the amount of debt it uses is denoted $D_{u p}(D$ still is the downstream party's debt level). Furthermore, the upstream party now can keep a share $\alpha \in(0,1)$ of the total relationship surplus, $\frac{\theta-c}{1-\delta}$, whereas the downstream party secures a share $1-\alpha$ (this allocation might for example be caused by a bargaining process at the beginning of every period). We impose no assumptions on the size $\alpha$, only that it leaves upstream and downstream party enough rent to render their ex-ante investments optimal. This implies that on-path payoffs are $\Pi=\frac{P+w-c}{1-\delta}=\frac{(1-\alpha)(\theta-c)-r D}{1-\delta}$ (downstream party) and $U=\frac{\theta-P-w}{1-\delta}=\frac{\alpha(\theta-c)-r D_{u p}}{1-\delta}$ (upstream party).

In the following, we will derive maximum debt thresholds for both parties for the two contractual arrangements formal spot and relational contracts (here, we abstract from formal enforcement in a long-term arrangement). There, we can omit the upstream party's (IR) condition, $U \geq 0$, which is automatically satisfied given starting its business is optimal for the upstream party (which is the case if $-I_{u p}+D+\delta U \geq 0$ and $D \leq I_{u p}$ ).

\section{Formal Spot Contract}

Here, we assume that upon not delivering high quality, the relationship is terminated (which is optimal following Abreu, 1988). Therefore, the upstream party's (IC) constraint equals 


$$
-c+P-r D_{u p}+\delta U \geq 0
$$

Taking into account $r=\frac{1-\delta}{\delta}$, this yields a a debt threshold $D_{u p} \leq D_{u p}^{F C}=\delta \frac{(P-c)(1-\delta)+\delta \alpha(\theta-c)}{1-\delta}$. The downstream party's no-default condition, $-r D+\delta \Pi \geq 0$, gives the downstream party's maximum debt threshold,

$$
D \leq D^{F C}=\frac{\delta^{2}(1-\alpha)(\theta-c)}{1-\delta}
$$

Hence, it is weakly optimal to set $P=\theta$ (this increases $D_{u p}^{F C}$ without affecting $D^{F C}$ ), therefore

$$
D_{u p}^{F C}=\delta \frac{(\theta-c)(1-\delta+\delta \alpha)}{1-\delta}
$$

\section{Relational Contract}

As with formal contracts, the upstream party's (IC) constraint equals $-c+P-r D_{u p}+$ $\delta U \geq 0$ and gives a debt threshold

$$
D_{u p} \leq D_{u p}^{R C}=\delta \frac{(1-\delta)(P-c)+\delta \alpha(\theta-c)}{1-\delta}
$$

Here, however, it is not necessarily optimal to set $P=\theta$, because a larger $P$ also reduces the downstream party's maximum debt threshold. This threshold is obtained by the dynamic enforcement constraint, $-P-r D+\delta \frac{(1-\alpha)(\theta-c)-r D}{1-\delta} \geq 0$, which yields

$$
D \leq D^{R C}=\delta \frac{\delta(1-\alpha)(\theta-c)-P(1-\delta)}{1-\delta}
$$

For given debt levels and if this is feasible, $P \in[c, \theta]$ will be designed such that both constraints hold. However, since $P \leq \theta, D_{u p}^{R C} \leq D_{u p}^{F C}$, whereas $P \geq c$ still implies $D^{R C}<D^{F C}$.

Therefore, the downstream party's maximum debt threshold is still strictly smaller under a relational than under a formal spot contract. The upstream party's maximum debt threshold is weakler smaller under a relational than under a formal spot contract.

\section{Appendix III - Changes in COEC Variable}




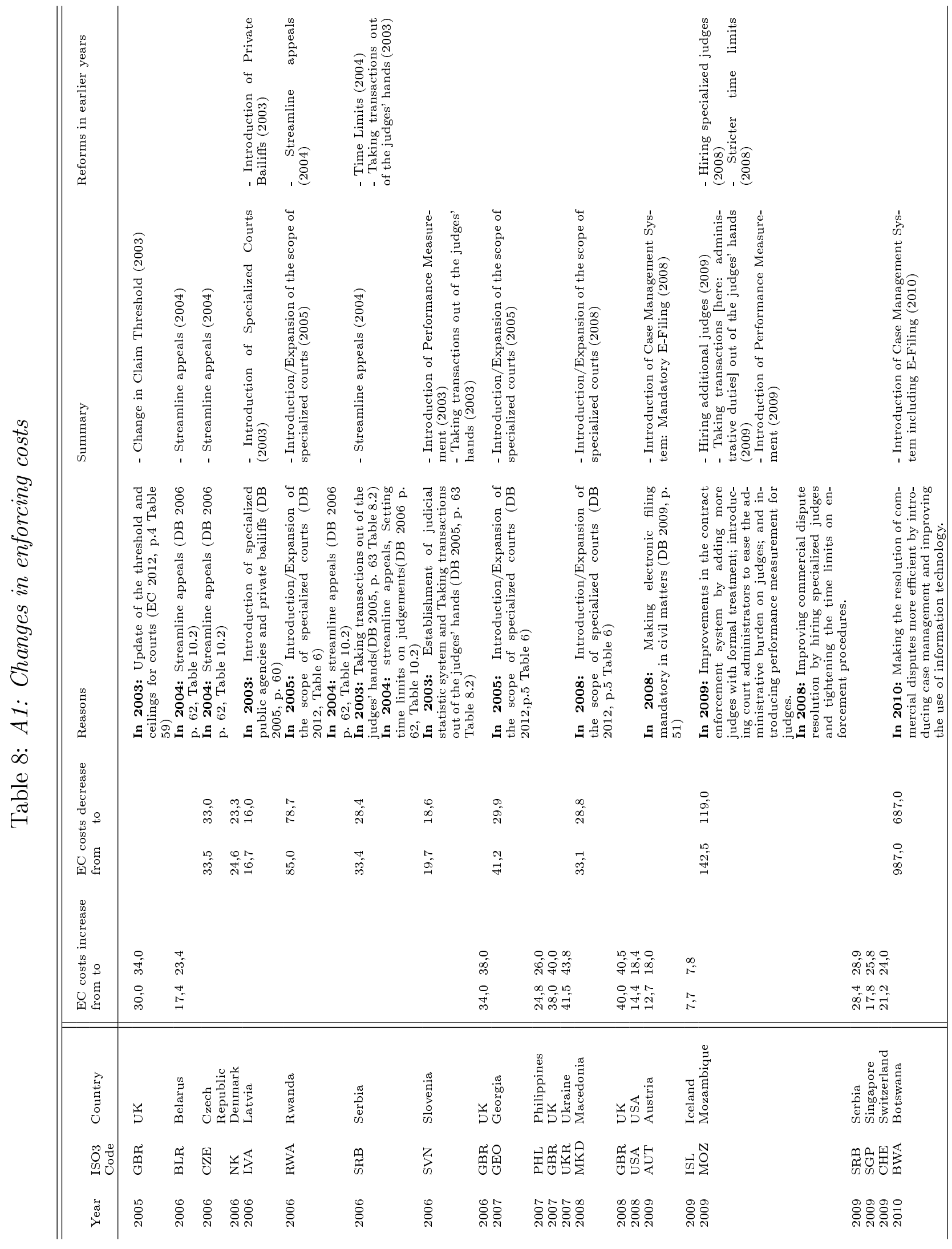




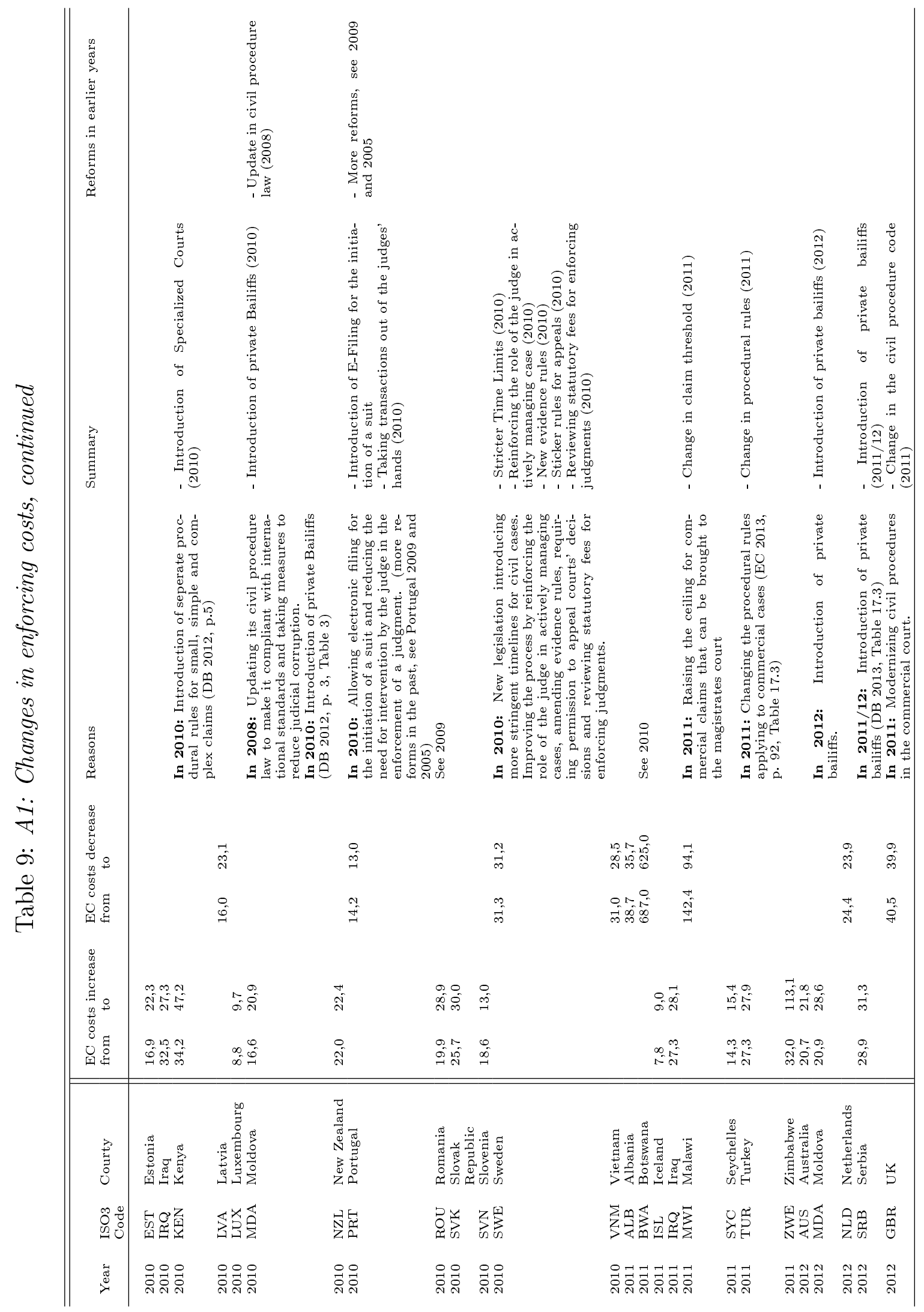

